\title{
Inclusion of mountain-wave-induced cooling for the formation of PSCs over the Antarctic Peninsula in a chemistry-climate model
}

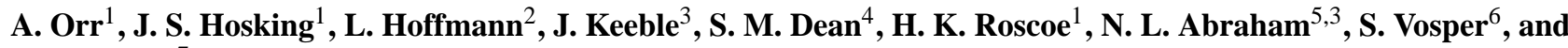 \\ P. Braesicke ${ }^{7}$ \\ ${ }^{1}$ British Antarctic Survey, NERC, Cambridge, UK \\ ${ }^{2}$ Jülich Supercomputing Centre, Forschungszentrum Jülich, Jülich, Germany \\ ${ }^{3}$ Department of Chemistry, University of Cambridge, Cambridge, UK \\ ${ }^{4}$ National Institute of Water and Atmospheric Research, Auckland, New Zealand \\ ${ }^{5}$ National Centre for Atmospheric Science, University of Cambridge, Cambridge, UK \\ ${ }^{6}$ Met Office, Exeter, UK \\ ${ }^{7}$ Karlsruhe Institute of Technology, Karlsruhe, Germany
}

Correspondence to: A. Orr (anmcr@bas.ac.uk)

Received: 31 May 2014 - Published in Atmos. Chem. Phys. Discuss.: 10 July 2014

Revised: 24 November 2014 - Accepted: 15 December 2014 - Published: 30 January 2015

\begin{abstract}
An important source of polar stratospheric clouds (PSCs), which play a crucial role in controlling polar stratospheric ozone depletion, is from the temperature fluctuations induced by mountain waves. However, this formation mechanism is usually missing in chemistry-climate models because these temperature fluctuations are neither resolved nor parameterised. Here, we investigate the representation of stratospheric mountain-wave-induced temperature fluctuations by the UK Met Office Unified Model (UM) at climate scale and mesoscale against Atmospheric Infrared Sounder satellite observations for three case studies over the Antarctic Peninsula. At a high horizontal resolution $(4 \mathrm{~km})$ the regional mesoscale configuration of the UM correctly simulates the magnitude, timing, and location of the measured temperature fluctuations. By comparison, at a low horizontal resolution $\left(2.5^{\circ} \times 3.75^{\circ}\right)$ the global climate configuration fails to resolve such disturbances. However, it is demonstrated that the temperature fluctuations computed by a mountain wave parameterisation scheme inserted into the climate configuration (which computes the temperature fluctuations due to unresolved mountain waves) are in relatively good agreement with the mesoscale configuration responses for two of the three case studies. The parameterisation was used to include the simulation of mountain-wave-induced PSCs in the global chemistry-climate configuration of the UM. A subsequent sensitivity study demonstrated that regional PSCs increased
\end{abstract}

by up to $50 \%$ during July over the Antarctic Peninsula following the inclusion of the local mountain-wave-induced cooling phase.

\section{Introduction}

Gravity waves generated by stratified flow passing over orography (mountain waves) that propagate into the stratosphere can play a role in the formation of polar stratospheric clouds (PSCs). Adiabatic temperature changes resulting from mountain-wave-induced vertical displacement can drive significant localised temperature fluctuations, enabling stratospheric temperatures to fall below the threshold value for PSC formation in the cold phases of these waves even if the synoptic-scale temperatures are too high. Studies of individual cases show that mountain waves formed over regions including the Antarctic Peninsula (AP), Greenland, and northern Scandinavia are a significant source of such clouds by generating localised cooling of up to $\sim 15 \mathrm{~K}$ (e.g. Carslaw et al., 1998a; Dörnbrack et al., 1999, 2002, 2012; Noel et al., 2009).

The threshold temperatures for PSC formation at an altitude of around $20 \mathrm{~km}$ depend on composition (in particular water vapour and nitric acid) and are generally assumed to be $195 \mathrm{~K}$ for type Ia (nitric acid trihydrate particles), $191 \mathrm{~K}$ 
for type $\mathrm{Ib}$ (supercooled ternary solution droplets), and $188 \mathrm{~K}$ for type II (water ice particles) (Pawson et al., 1995; Alfred et al., 2007). Within the centre of the Antarctic stratospheric vortex in winter, the atmosphere is so cold that temperatures are regularly below these thresholds, i.e. formation of PSCs on the synoptic scale dominates (Campbell and Sassen, 2008). However, the synoptic-scale temperatures of the edge region of the Antarctic stratospheric vortex can be warmer than the formation thresholds, and therefore not typically saturated in PSCs in winter and early spring. Hence, mountain waves can be an important source of PSCs at the edge region of the Antarctic stratospheric vortex, such as over the AP (McDonald et al., 2009; Noel and Pitts, 2012). Because of stronger planetary wave forcing, the Arctic stratospheric vortex is generally considerably warmer than that of the Antarctic. Thus, the occurrence of PSC formation temperatures on the synoptic scale is less frequent in the Arctic (Pawson et al., 1995), thereby making mountain-wave-induced PSCs an important source (Dörnbrack et al., 2001; Alexander et al., 2013). Moreover, mountain waves are a significant source of PSCs on the synoptic scale in both the Arctic and Antarctic due to their advection far downstream of the wave event that formed them (Carslaw et al., 1999; Höpfner et al., 2006; Eckermann et al., 2009; Alexander et al., 2011).

The role of PSC particles in polar ozone chemistry is well understood. In the winter, when there is not enough sunlight in the polar stratosphere to initiate photochemistry, the conversion of reservoir chlorine molecules into chlorine gas takes place on the surface of PSCs. In the spring, when the polar stratosphere becomes sunlit, ultraviolet radiation splits the chlorine gas molecules into chlorine atoms, which take part in reactions which destroy ozone (Solomon, 1999). These reactions have resulted in the formation of the springtime Antarctic ozone hole, which has profoundly impacted the Southern Hemisphere circulation and surface climate during summer (e.g. Orr et al., 2008, 2012; Thompson et al., 2011). With the continued implementation of the Montreal Protocol, recovery of the Antarctic ozone hole is generally anticipated by the end of the century. However, model predictions using coupled chemistry-climate simulations give a large range of estimates of the rate and timing of this recovery (Eyring et al., 2013). The fact that the results are modeldependent suggests that some mechanisms are not yet fully understood. Similarly, simulations of the ozone hole covering the past few decades obtain a wide range of results, further questioning the value of these predictions (Austin et al., 2010). Accurate predictions of the timing are critical as this recovery will reshape Southern Hemisphere climate by no longer counteracting the effects of increasing greenhouse gases (Polvani et al., 2011).

Therefore, to produce accurate simulations of stratospheric ozone depletion, coupled chemistry-climate models must be able to represent PSC formation mechanisms and their attendant ozone-loss chemistry due to localised dynamics such as mountain waves (Cariolle et al., 1989; Carslaw et al., 1998b; Austin et al., 2010). However, current global chemistry-climate models have a horizontal resolution of some hundreds of kilometres (e.g. Morgenstern et al., 2010) at the Equator and are therefore only able to explicitly resolve waves with long horizontal wavelengths (Reinecke and Durran, 2009), i.e. the temperature fluctuations associated with small-scale mountain waves are missing, leading to insufficient PSC formation in the models. Consistent with this is the systematic over-prediction of high-latitude springtime ozone increases in both hemispheres by models (Carslaw et al., 1998b; Eyring et al., 2006).

Mountain-wave-induced stratospheric temperature fluctuations can be detected by their associated fluctuations in temperature-sensitive satellite radiance measurements from infrared scanning instruments such as the Atmospheric Infrared Sounder (AIRS) (e.g. Alexander and Barnet, 2007; Hoffmann et al., 2013). As a nadir-viewing instrument, AIRS radiance measurements have a high horizontal resolution (14 km at nadir), enabling waves with short horizontal scales which are unresolved by chemistry-climate models to be visible. On the other hand, AIRS radiance measurements have a limited vertical resolution, meaning waves with short (typically $\leq 10 \mathrm{~km}$ ) vertical scales are poorly resolved. Comparison between AIRS radiance measurements and modelsimulated radiance measurements (calculated using the simulated temperature field of the model as input for a radiative transfer model) provides an effective and direct means of validation of the model representation of gravity wave events (Grimsdell et al., 2010).

To improve the simulation of mountain-wave-induced PSCs in a chemistry-climate model, the temperature fluctuations due to unresolved (sub-grid-scale) mountain waves can be parameterised (e.g. Carslaw et al., 1999; Dean et al., 2007; Wells et al., 2011). In the parameterisation scheme of Dean et al. (2007) the mountain-wave-induced temperature fluctuations were used in the cloud scheme of the HadAM3 (Hadley Centre Atmospheric Model version 3) configuration of the Met Office Unified Model (UM) to realistically represent cirrus in the upper troposphere, which was previously under-represented over many mountain ranges.

In this study, the Dean et al. (2007) scheme is used to include the simulation of mountain-wave-induced PSCs in the global chemistry-climate configuration of the UM (Sect. 5). However, we only evaluate the sensitivity of PSC simulation in the chemistry-climate model to the inclusion of the mountain-wave-induced temperature fluctuations for one regional example, the AP. (The contribution of the scheme to global PSCs and ozone chemistry will be fully assessed in a subsequent manuscript.) This is because the main purpose of this study is to assess the ability of the parameterisation to simulate stratospheric temperature fluctuations, which is achieved by using case studies of AIRS measurements to validate high horizontal resolution simulations (using the regional mesoscale configuration of the UM) of mountainwave-induced stratospheric temperature fluctuations above 
the AP (Sect. 3). Following this, the Dean et al. (2007) scheme is inserted into the (low horizontal resolution) global climate configuration of the UM and its temperature fluctuations are assessed by comparing with output from the highresolution simulations (Sect. 4). We will demonstrate below that the high-resolution simulations are in excellent agreement with the AIRS observations and can therefore be used as a "truth" with which to investigate the performance of the parameterisation scheme.

The AP is chosen because strong westerly winds impinging on its high topographic ridge frequently generate largeamplitude stratospheric mountain waves (Plougonven et al., 2008; Hoffmann et al., 2013) with horizontal wavelengths of $\sim 300 \mathrm{~km}$ (as well as structures on shorter horizontal scales) and long ( $\geq 10 \mathrm{~km}$ ) vertical wavelengths (Wu, 2004; Alexander and Teitelbaum, 2007), i.e. resolved by AIRS. The long vertical wavelengths result from wave refraction caused when the background wind speed is unidirectional and increases with height (see e.g. Wu and Eckermann, 2008). Note also that the availability of sunlight at the AP during midwinter to initiate photochemistry means that ozone depletion is substantial over this region from mid-winter onwards (Roscoe et al., 1997).

\section{Models, mountain wave parameterisation, data, and methodology}

\subsection{Models}

The UM is a numerical modelling system based on nonhydrostatic dynamics which can be run with varying configurations, including for this study as a regional mesoscale model, a global climate model, and a global chemistryclimate model. Hereafter, these models are referred to as the mesoscale, climate, and chemistry-climate models, respectively. The climate model is based on the HadGEM3 (Hadley Centre Global Environmental Model version 3) configuration of the UM (Hewitt et al., 2011). The chemistry-climate model couples the United Kingdom Chemistry and Aerosol (UKCA) module to the UM climate configuration (Morgenstern et al., 2009). UKCA uses a simplified scheme for forming and evaporating PSCs, based on the assumption that the gas and condensed phases of $\mathrm{HNO}_{3}$ are in equilibrium (Morgenstern et al., 2009). Here, both the climate and chemistryclimate configurations are atmosphere-only models based on version 7.3 of the UM, with a horizontal resolution of $\mathrm{N} 48$ $\left(96 \times 73\right.$ grid points, or $\left.2.5^{\circ} \times 3.75^{\circ}\right)$ and 60 vertical levels (going up to $84 \mathrm{~km}$ ). Version 7.3 of the UM was selected for the global modelling exercise because of its current use in a recent, comprehensive model inter-comparison (SPARC, 2013).

The mesoscale model is based on version 7.6 of the UM, and is similar to that described in Orr et al. (2014). It is atmosphere-only with a model domain centred over the AP, comprising $388 \times 460$ grid points with a horizontal resolution of $4 \mathrm{~km}$ and 85 vertical levels (reaching up to $85 \mathrm{~km}$ ). Following Webster et al. (2008), it uses the option of a fully three-dimensional potential temperature advection scheme, in conjunction with reduced temporal off-centring, to better represent resolved gravity waves. Orography is interpolated from a high-resolution digital elevation model of Antarctica (version 9 of the Radarsat Antarctic Mapping Project; Liu et al., 2001). The mesoscale model is nested within a global version of the model with a horizontal resolution of N512 $\left(1024 \times 769\right.$ grid points, or $\left.0.352^{\circ} \times 0.234^{\circ}\right)$ and 70 vertical levels (reaching up to $80 \mathrm{~km}$ ) that is used (following a $3 \mathrm{~h}$ spin-up) to initiate and provide boundary conditions for the simulation. Note that initialisation values for sea ice state and sea-surface temperature for the mesoscale model were obtained from high-resolution ( $\sim 5 \mathrm{~km}$ scale) daily Operational Sea Surface Temperature and Sea Ice Analysis (OSTIA) data (Donlon et al., 2011). The Met Office operational analysis is used to initialise the global model. Version 7.6 of the UM was selected for the mesoscale model as it included improvements which reduced the occurrence of spurious cooling in partially resolved valleys.

Note that all of the configurations of the UM parameterise the vertical divergence of mountain-wave-induced momentum flux (i.e. orographic gravity wave drag), which influences the atmospheric circulation. This is dealt with by the orographic gravity wave drag scheme of Webster et al. (2003), which should not be confused with the mountainwave-induced temperature fluctuation scheme of Dean et al. (2007), described below.

\subsection{Description of the mountain wave parameterisation}

By assuming that waves are forced by steady flow over a twodimensional ridge and that vertical variations of the background atmospheric state are slowly varying (compared to the wave phase), the scheme described by Dean et al. (2007) derives generalised expressions for the maximum and minimum vertical streamline displacement (resulting in cooling and warming, respectively) associated with gravity waves induced by sub-grid-scale orography (SSO). These expressions are used to compute the maximum negative $\Delta T_{\mathrm{SSO}}^{-}$ and positive $\Delta T_{\mathrm{SSO}}^{+}$temperature fluctuations associated with the displacement, which are derived using the local potential temperature gradient (Wells et al., 2011). The overall temperature fluctuation induced is subsequently calculated as $\Delta T_{\mathrm{SSO}}=\Delta T_{\mathrm{SSO}}^{+}+\Delta T_{\mathrm{SSO}}^{-}$. Waves are launched at every model grid box over land and at every model time step.

The expressions for the maximum and minimum streamline displacement depend on both the wave phase and peak vertical streamline displacement amplitude (hereafter referred to as wave amplitude), which are determined as follows. The vertical propagation is based on linear theory for hydrostatic waves forced by steady, stably stratified flow over a two-dimensional ridge, assuming that vertical varia- 
tions of the background atmospheric state are slowly varying. McFarlane (1987) showed that under these circumstances and in the absence of dissipation mechanisms the vertical evolution of the wave amplitude is determined by the decrease in density of the atmosphere with height and by changes in the horizontal wind speed $U$ (resolved in the direction of the wave vector) and the Brunt-Väisälä frequency $N$. Dissipation mechanisms such as wave breaking and critical-level absorption are introduced by preventing the amplitude from exceeding the local "saturation amplitude" for which the wave field becomes unstable $\left(=U / N F_{\text {sat }}\right.$, where $F_{\text {sat }}$ is the critical Froude number for saturation). The vertical evolution of the wave phase is determined by changes in $U$ and $N$, i.e. the Scorer parameter $l(N / U)$.

To complete the determination of the wave phase and amplitude, their initial values at the top of the blocked layer must be decided. The initial wave phase is set equal to zero. The initial wave amplitude is set equal to the "effective" mountain height $h_{\text {eff }}$ (i.e. $h-h_{\mathrm{b}}$, where $h$ is the height of the sub-grid-scale mountain and $h_{\mathrm{b}}$ is the height of the blocked layer that occurs at low Froude number), i.e. the maximum vertical displacement of streamlines able to pass over the top of the mountain. This is strongly dependent on the direction of the low-level wind relative to the principle axis of the SSO (which preferentially aligns as ridges), and ensures that the surface amplitude is large (small) when the wind is perpendicular (parallel) to a ridge. Here, $h=n_{\sigma} \sigma$, where $\sigma$ is the standard deviation of the SSO height from the grid-box mean and $n_{\sigma}$ is a constant (such that $n_{\sigma} \sigma$ approximates the physical envelope of the peaks), and $h_{\mathrm{b}}=h-U_{0} / N_{0} F_{\mathrm{c}}$, where $F_{\mathrm{c}}$ is the critical Froude number at which flow blocking is deemed to first occur, and the subscript " 0 " refers to the surface layer, represented by averaging $U$ and $N$ between the surface and $h$. Note that to implement the directional dependence of the surface amplitude, $U_{0}$ is resolved in the direction perpendicular to the principle axis of the sub-grid orography (i.e. the direction of the wave vector). This differs from the implementation in Dean et al. (2007), which represents the directional dependence by defining the standard deviation $\sigma$ of the SSO height in the surface wind direction.

The parameterisation scheme is (globally) implemented in the climate and chemistry-climate configurations of the UM. The SSO parameters used by the scheme are based on Lott and Miller (1997). In the scheme, the parameters $n_{\sigma}, F_{\text {sat }}$, and $F_{\mathrm{c}}$ are treated as tuneable. Following an initial sensitivity study (specific to the AP, not shown) to optimise the performance of the scheme, their values were set to $n_{\sigma}=3$, $F_{\text {sat }}=2$, and $F_{\mathrm{c}}=4$.

\subsection{Data}

AIRS (Aumann et al., 2003) is aboard NASA's Aqua satellite, which was launched in May 2002. AIRS measures the thermal emissions of atmospheric constituents in the nadir and sub-limb observation geometry. An across-track scan consists of 90 individual footprints and covers a distance of $1765 \mathrm{~km}$ on the ground. The along-track distance between two scans is $18 \mathrm{~km}$. The AIRS aperture is $1.1^{\circ}$, corresponding to a horizontal resolution of $13.5 \mathrm{~km}$ at nadir and $41 \mathrm{~km} \times 21.4 \mathrm{~km}$ at the scan extremes. The AIRS radiance measurements cover wavelength ranges from 3.74 to $15.4 \mu \mathrm{m}$ with a total of 2378 radiance channels. The absolute error of the radiometric calibration is less than $0.2 \%$. The noiseequivalent delta temperature is about $0.39 \mathrm{~K}$ at $250 \mathrm{~K}$ scene temperature for the spectral channel $\left(666.5 \mathrm{~cm}^{-1}\right)$ considered here. The analyses presented in this paper are based on consolidated version 5 data products made freely available by NASA. The equatorial crossing of Aqua occurs at 13:30 LT (ascending orbit) and 01:30 LT (descending orbit). At high latitudes there is a quick transition between day- and nighttime observations (e.g. Hoffmann et al., 2013). The AP is typically covered by four satellite overpasses per day. A more detailed description of AIRS is given in, for example, Hoffmann and Alexander (2009, 2010), Grimsdell et al. (2010), and Hoffmann et al. (2013).

Infrared radiance measurements in the 4.3 and $15 \mu \mathrm{m} \mathrm{CO} 2$ bands are of particular interest for the study of stratospheric gravity waves. These spectral bands get optically thick in the stratosphere and provide direct information on atmospheric temperature at this level. Hoffmann and Alexander (2009) show the temperature kernel functions for the individual AIRS channels covering the 4.3 and $15 \mu \mathrm{m} \mathrm{CO} 2$ bands. In this study we selected the $666.5 \mathrm{~cm}^{-1}$ radiance channel of AIRS, which is within the $15 \mu \mathrm{m} \mathrm{CO}_{2}$ band. The temperature weighting function of this channel is given in Fig. 1, which shows that the brightness temperatures (BTs) are most sensitive to atmospheric temperature at an altitude of $22 \mathrm{~km}$, with full width at half maximum of $9 \mathrm{~km}$. The altitude range covered by the $666.5 \mathrm{~cm}^{-1}$ channel is of particular interest for the formation of PSCs. As the kernel function drops to less than $1 \%$ of maximum sensitivity below $14 \mathrm{~km}$, there is little interference from tropospheric emissions from clouds or water vapour.

\subsection{Methodology}

Three instances of stratospheric mountain waves observed over the AP by AIRS, characterised by large amplitude and long vertical wavelength, occurred on 7 August 2011 at 03:40 UTC (case study 1, hereafter CS1), 2 August 2010 at 18:59 UTC (case study 2, hereafter CS2), and 14 July 2010 at 20:00 UTC (case study 3, hereafter CS3). These events were simulated by running the mesoscale model nested within a global model version of the model initialised on 5 August 2011 at 12:00 UTC for CS1, 1 August 2010 at 00:00 UTC for CS2, and 13 July 2010 at 00:00 UTC for CS3. The mesoscale model output times (integration time) closest to the actual measurement time are at 03:00 UTC on $7 \mathrm{Au}-$ gust $2011(\mathrm{~T}+39 \mathrm{~h})$ for CS1, at 19:00 UTC on 2 August $2010(\mathrm{~T}+43 \mathrm{~h})$ for CS2, and at 20:00 UTC on 14 July 2010 


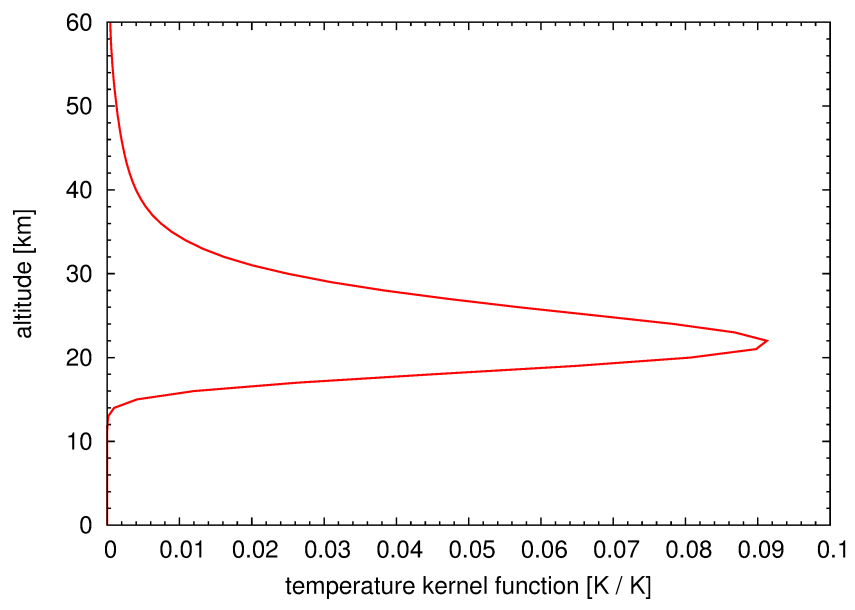

Figure 1. The temperature weighting function (brightness temperature $(\mathrm{K}) /$ temperature $(\mathrm{K})$ ) for the $666.5 \mathrm{~cm}^{-1}$ AIRS channel. This function was calculated for a polar winter reference atmosphere, a $1 \mathrm{~km}$ altitude grid, and the nadir observation geometry.

$(\mathrm{T}+44 \mathrm{~h})$ for CS3 (note that for simplicity the mesoscale model integration times are given relative to the time of the global model initialisation). The output times reflect that the simulation of the mountain wave field requires at least a $24 \mathrm{~h}$ spin-up (Plougonven et al., 2010). Table 1 summarises this information. Figure 2 shows the near-surface $(850 \mathrm{hPa})$ wind field simulated by the mesoscale model at the output time for each case study, showing that each of the mountain wave events were coincident with strong westerly or northwesterly winds incident to the AP. These winds showed the requisite strengthening with height required for the mountain waves to have long vertical wavelengths which were visible to AIRS (not shown).

To verify the mesoscale model simulations, the Juelich Rapid Spectral Simulation Code (JURASSIC) radiative transfer model (Hoffmann and Alexander, 2009) was used to compute model-simulated AIRS radiances at $666.5 \mathrm{~cm}^{-1}$. For comparison, both the real and mesoscale-modelsimulated AIRS radiances are subsequently converted into their corresponding BT values. Brightness temperature perturbations $\triangle \mathrm{BT}$ were computed by removing a background brightness temperature, which was determined by fitting a fourth-order polynomial (e.g. Wu, 2004; Alexander and Barnet, 2007; Hoffmann and Alexander, 2010). This fit removes slowly varying atmospheric signals, e.g. from planetary waves and general scan-angle dependence of radiances due to the sub-limb geometry. For the AIRS measured radiances the fit was carried out for each scan in the acrosstrack direction; for the mesoscale-model-simulated radiances it was carried out for each latitudinal band of the model grid. In both cases it was found that the fits are well constrained by the data and the process did not introduce any artificial wave-like structures that could obfuscate the results. In order to avoid the suppression of waves with fronts parallel
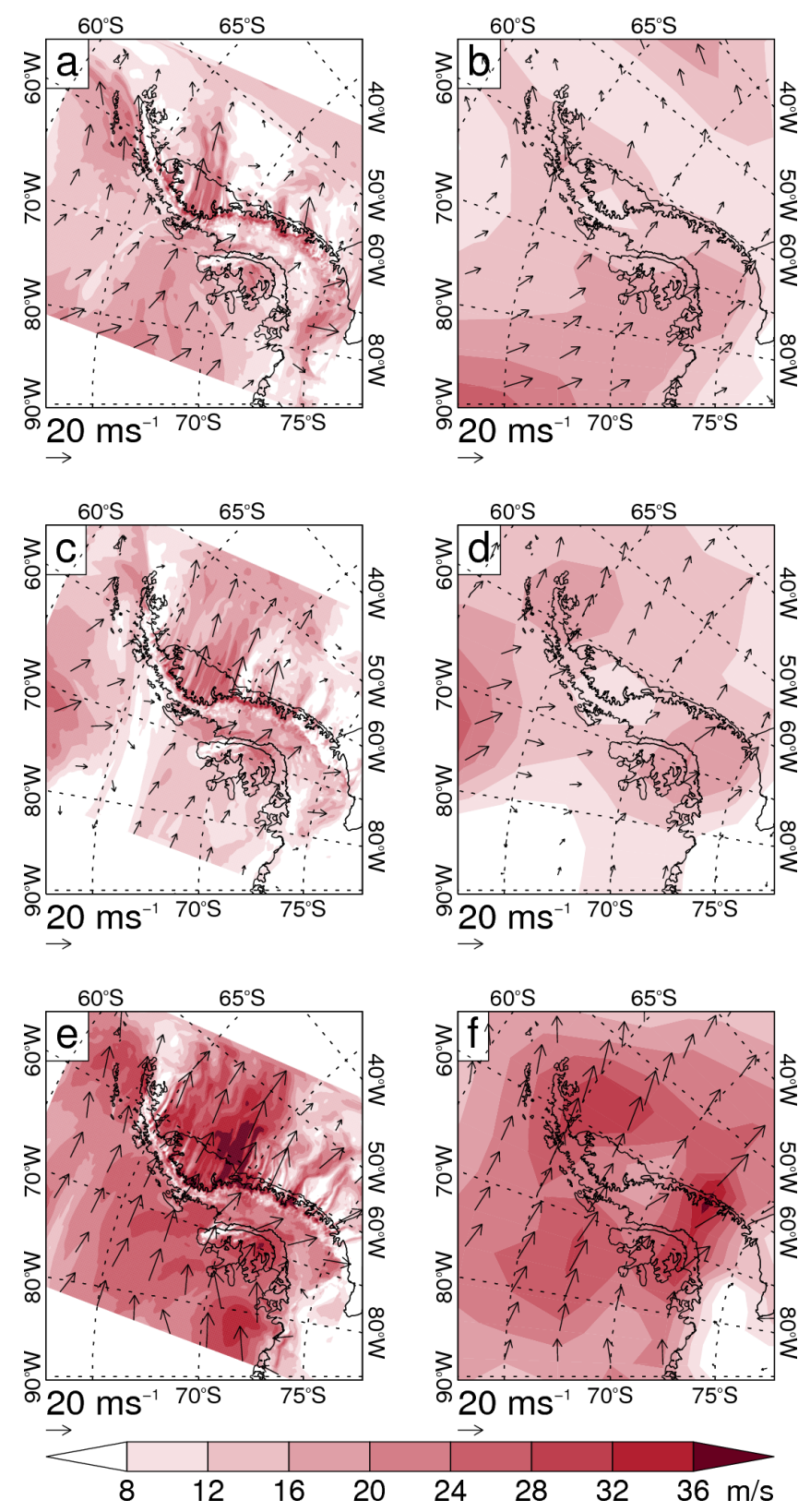

Figure 2. Mesoscale model (left) and climate model (right) simulation of the $850 \mathrm{hPa}$ wind field $\left(\mathrm{m} \mathrm{s}^{-1}\right)$ over the AP at the time of the CS1 (a, b), CS2 (c, d), and CS3 (e, f) mountain wave events. See Table 1 for dates. The black arrows are wind vectors (for the mesoscale model only 1 in every 40 grid points is shown). The colour shading indicates the wind speed. Also shown is the coastline of the AP.

to the fit direction the AIRS measured (simulated), background estimates were smoothed by a $300 \mathrm{~km}$ running mean in the along-track (longitudinal) direction. Finally, mesoscale model estimates of $\triangle \mathrm{BT}$ are re-gridded to the AIRS measurement grid. 
Table 1. Dates and times of the three mountain wave case studies for the AIRS measurements, the start of the mesoscale and climate model simulations, and the model output time nearest the AIRS measurements (in UTC).

\begin{tabular}{lrrr}
\hline Case study & $\begin{array}{r}\text { AIRS } \\
\text { measurement }\end{array}$ & Model start & $\begin{array}{r}\text { Model output time nearest } \\
\text { the AIRS measurement }\end{array}$ \\
\hline $\mathrm{CS} 1$ & 7 Aug 2011, 03:40 & 5 Aug 2011, 12:00 & 7 Aug 2011,03:00 $(\mathrm{T}+39 \mathrm{~h})$ \\
$\mathrm{CS} 2$ & 2 Aug 2010, 18:59 & 1 Aug 2010, 00:00 & 2 Aug 2010, 19:00 $(\mathrm{T}+43 \mathrm{~h})$ \\
$\mathrm{CS} 3$ & 14 Jul 2010, 20:00 & 13 Jul 2010, 00:00 & 14 Jul 2010, 20:00 $(\mathrm{T}+44 \mathrm{~h})$ \\
\hline
\end{tabular}

The mesoscale model simulations of the three case studies were repeated using the climate model (i.e. the climate model is initialised using the same Met Office operational analysis and integrated forward in time for $48 \mathrm{~h}$ ). Comparison of the mesoscale model and climate model simulations of the near-surface winds at the time of the mountain wave events (Fig. 2) shows relatively small differences in the large-scale flow impacting the AP, i.e. the large-scale atmospheric conditions responsible for the initial forcing of the mountain waves are broadly similar in both models. As the mountain wave parameterisation scheme is implemented in the climate model, the temperature fluctuations over the AP predicted by the scheme $\Delta T_{\mathrm{SSO}}$, as well as the temperature fluctuations explicitly resolved by the climate model $\Delta T_{\text {CLIM }}$ (computed by removing the background temperature, determined by fitting a fourth-order polynomial), can be assessed by comparing with those from the mesoscale model. Using the mesoscale model simulations enables investigation of the vertical profile of the parameterised output, in particular the vertical evolution of the wave phase, which is not possible at good vertical resolution using AIRS data alone. In the climate model implementation, $\Delta T_{\mathrm{SSO}}$ is passed solely to the model output to enable its evaluation and is not used by the dynamical core or any other parameterisation scheme.

Finally, to assess the sensitivity of the PSC scheme used by the UKCA chemistry module to the mountain wave parameterisation, perturbation and control experiments using the chemistry-climate model were conducted. The equilibrium PSC scheme provides a realistic representation of the existence of PSC particles when air temperatures drop below the PSC temperature formation threshold (e.g. Feng et al., 2011). However, the scheme does not represent a slow decline of PSC existence when temperatures rise abruptly above the temperature threshold. Instead, PSCs cease to exist instantaneously in the scheme. For this reason only the cooling-phase $\Delta T_{\mathrm{SSO}}^{-}$of the parameterised temperature fluctuations are coupled to the PSC scheme as the net impact on additional PSC formation will be more realistic. Consequently the warm phase is neglected and the net effect on PSC existence might be slightly overestimated. Carslaw et al. (1999) argue that this approach is also physically justified as the warming phase of the wave-induced temperature fluctuations is typically of short enough duration that the complete evaporation of the PSC particles is unlikely to occur before temperatures fall again. In addition, evaporation will not occur if the synoptic-scale temperatures are sufficiently low that the warming phase still results in the temperature being below the PSC threshold value. In the perturbation experiments the mountain wave parameterisation is switched on. The PSC scheme computes a "total" temperature, used only by itself, by combining the temperature explicitly resolved by the chemistry-climate model $T_{\text {CHEM-CLIM }}$ with $\Delta T_{\mathrm{SSO}}^{-}$. In the control experiment the mountain wave scheme is switched off. Both the perturbation and control experiments were run for 30 years (following a 30-year spin-up period) for a perpetual year 2000, using prescribed sea-surface temperature and sea ice fraction. For this part of the study we again concentrate on results for the AP, focusing on the month of July.

\section{Mesoscale model verification}

Figure 3 compares maps of measured and mesoscale-modelsimulated estimates of $\triangle \mathrm{BT}$ for each of the three case studies. In the left panels the measured field $\Delta \mathrm{BT}_{\mathrm{AIRS}}$ shows warm and cold temperature disturbances of amplitude $2-3 \mathrm{~K}$ clearly aligned with the western side of the AP mountain ridge, i.e. typical of phase fronts associated with a mountain wave caused by low-level westerly flow passing over the AP and propagating upward in the atmosphere. In the right panels the amplitude and structure of the corresponding mesoscale model field $\triangle \mathrm{BT}_{\mathrm{MES}}$ agrees well with the measurements.

Figure 4 compares $\triangle \mathrm{BT}_{\mathrm{AIRS}}$ and $\triangle \mathrm{BT}_{\mathrm{MES}}$ in more detail by examining their variation along the west-east-orientated lines displayed in Fig. 3. The mountain wave appears prominently in both fields, with the mesoscale model producing a similar-looking temperature disturbance to that measured. There are slight differences in terms of the wave amplitude, e.g. the mesoscale model amplitude in CS3 is slightly larger than that measured.

Note that in addition to a coherent mountain wave structure, Figs. 3 and 4 also show highly localised temperature fluctuations. For AIRS these fluctuations are partly due to increasing instrumental noise with low scene temperatures. The nominal noise of $0.39 \mathrm{~K}$ at $250 \mathrm{~K}$ scene temperature scales to $0.67-0.78 \mathrm{~K}$ at $190-200 \mathrm{~K}$, which is more representative for the situations observed here. 

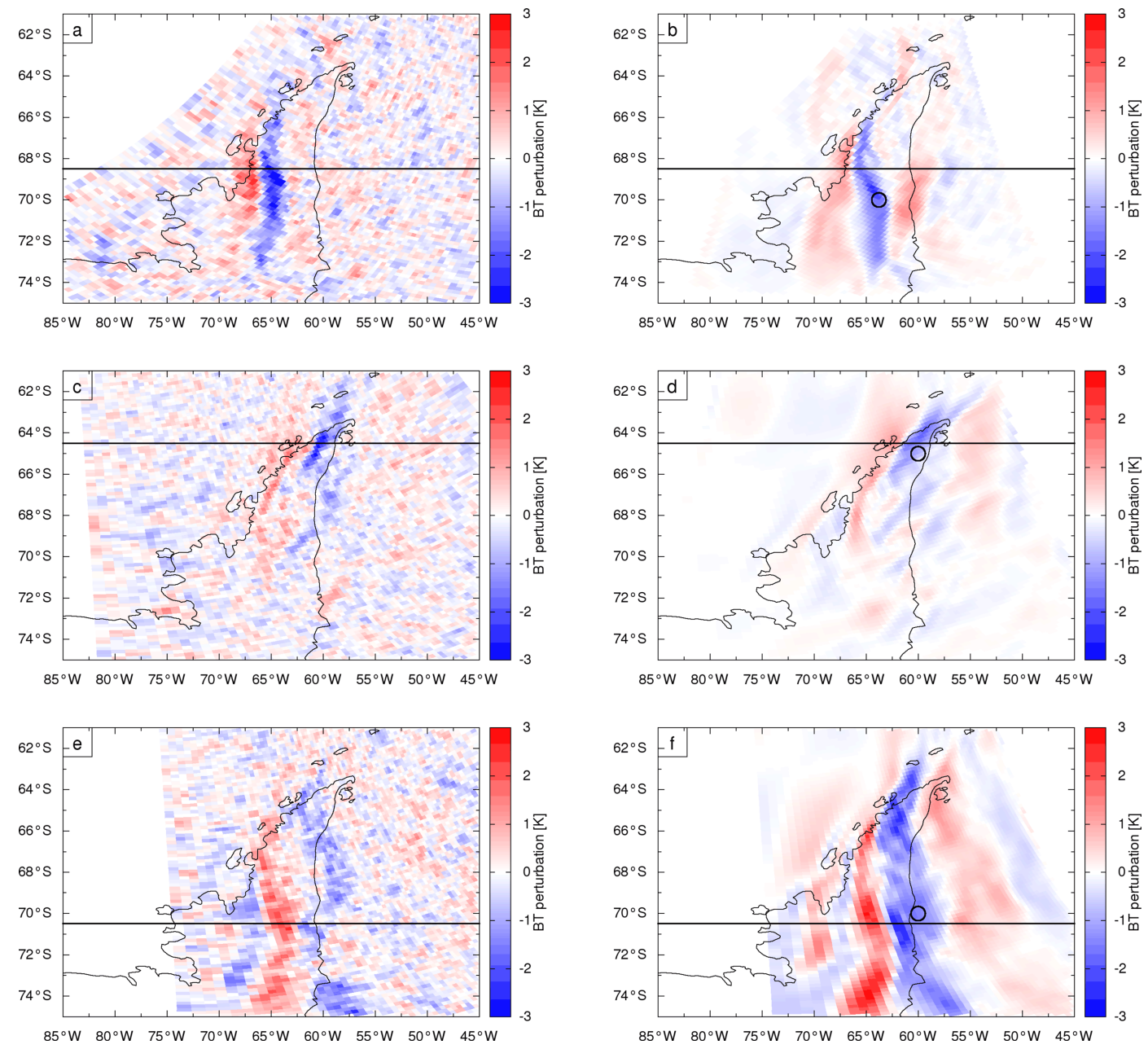

Figure 3. Measured (left) and mesoscale model (right) estimates of brightness temperature perturbations (K) over the AP corresponding to the $666.5 \mathrm{~cm}^{-1}$ AIRS channel at the time of the CS1 (a, b), CS2 (c, d), and CS3 (e, f) mountain wave events. See Table 1 for dates. The horizontal black lines indicate the latitude band selected for a more detailed comparison, shown in Fig. 4. The black circles in panels (b), (d), and (f) show the location of the climate model grid boxes used in Figs. 5, 7, and 8. Also shown is the coastline of the AP.

\section{Assessment of the mountain wave parameterisation}

Having shown a very good comparison between measured and mesoscale-model-simulated $\triangle \mathrm{BT}$ over the $\mathrm{AP}$, we can now use the temperature fluctuations simulated by the mesoscale model $\Delta T_{\mathrm{MES}}$ to assess the parameterised temperature fluctuations $\Delta T_{\mathrm{SSO}}$, as well as the temperature fluctuations explicitly resolved by the climate model $\Delta T_{\text {CLIM }}$. Due to the occurrence of spatially highly localised and strongly varying temperature fluctuations, the fairest approach is to compare profiles of $\Delta T_{\mathrm{SSO}}$ and $\Delta T_{\mathrm{CLIM}}$ for a particular $\left(2.5^{\circ} \times 3.75^{\circ}\right)$ climate model grid box with the mean and spread ( \pm 2 standard deviations) of $\Delta T_{\mathrm{MES}}$ for all the mesoscale model points within the same $\left(2.5^{\circ} \times 3.75^{\circ}\right)$ climate model grid box. The representative climate model grid boxes for each of the three case studies are selected to coincide with the location of their respective mountain wave events. With Fig. 3 used for guidance, the grid boxes are located at $\left(70^{\circ} \mathrm{S}, 63.75^{\circ} \mathrm{W}\right)$ for $\mathrm{CS} 1,\left(65.0^{\circ} \mathrm{S}, 60.0^{\circ} \mathrm{W}\right)$ for $\mathrm{CS} 2$, and $\left(70.0^{\circ} \mathrm{S}, 60^{\circ} \mathrm{W}\right)$ for $\mathrm{CS} 3$ (these locations are also shown in Fig. 3). The comparison in Fig. 5 shows that for two of the case studies (CS1 and CS3) that $\Delta T_{\mathrm{SSO}}$ and the mean $\Delta T_{\mathrm{MES}}$ response are in relatively good agreement in terms of amplitude (which ranges from 0 to $10 \mathrm{~K}$ in the lower stratosphere), while $\Delta T_{\mathrm{SSO}}$ and the mean $\Delta T_{\mathrm{MES}}$ response are slightly out of alignment in terms of phase, evident by the maximum and minimum values of $\Delta T_{\mathrm{SSO}}$ differing by roughly $1 \mathrm{~km}$ from the mean $\Delta T_{\mathrm{MES}}$ response. However, at all altitudes, $\Delta T_{\mathrm{SSO}}$ lies within the spread of $\Delta T_{\mathrm{MES}}$ (which in CS3 exceeds $\pm 15 \mathrm{~K}$ in the lower stratosphere), suggesting that the parameterised temperature fluctuations are representative of the range of mesoscale model responses. By contrast, in CS2 the agreement between $\Delta T_{\mathrm{SSO}}$ and the mean $\Delta T_{\mathrm{MES}}$ response is poor, marked by the failure of the parameterised response to suggest any temperature fluctua- 

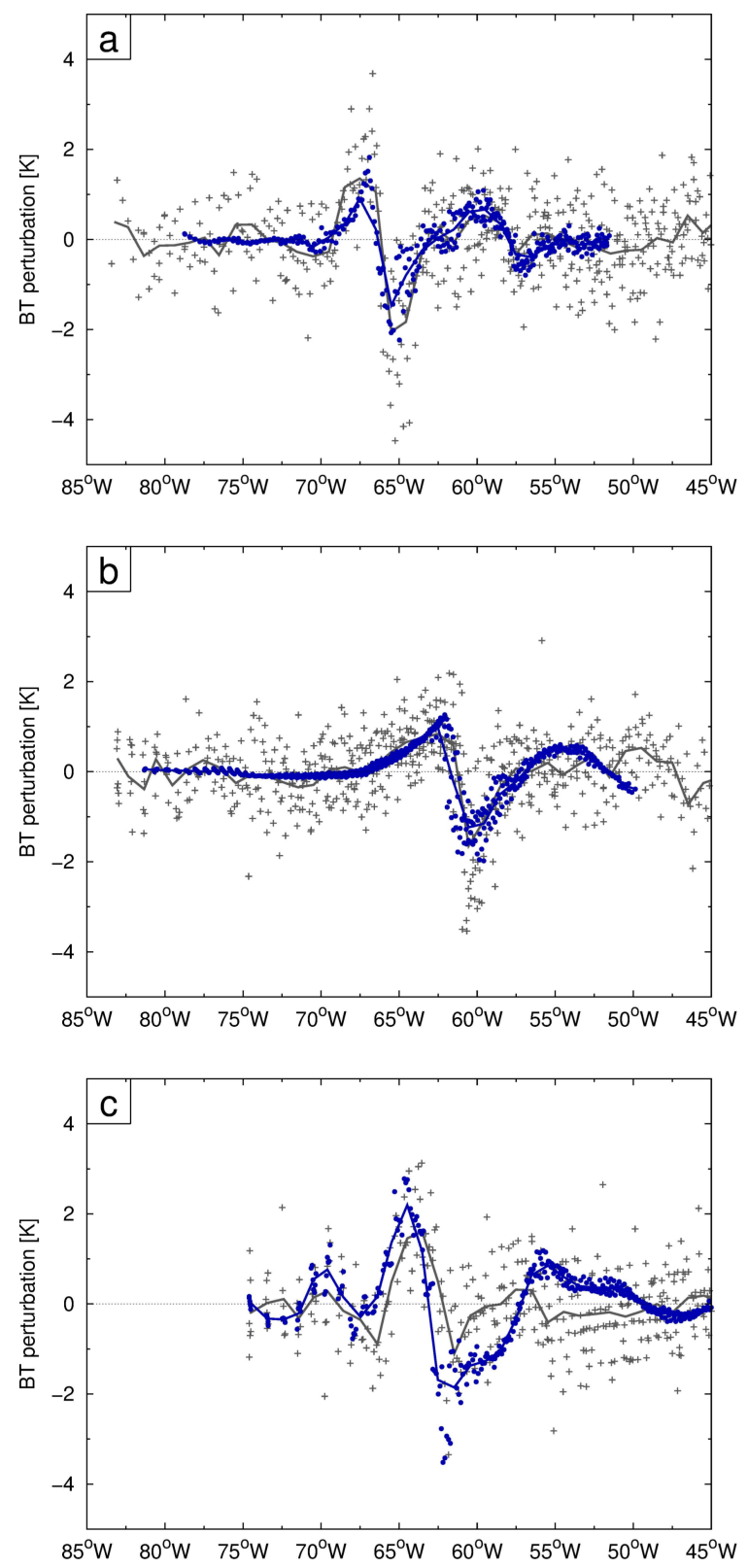

Figure 4. Measured (grey) and mesoscale-model-simulated (blue) brightness temperature fluctuations $(\mathrm{K})$ corresponding to the $666.5 \mathrm{~cm}^{-1}$ AIRS channel along a latitude band intersecting the AP (indicated in Fig. 3) at the time of the CS1 (a), CS2 (b), and CS3 (c) mountain wave events. See Table 1 for dates. Model data have been re-sampled on the AIRS measurement grid. Note that the model domain does not always cover the full AIRS swath; therefore re-gridded model data are missing at some longitudes in CS1 and CS2. The solid lines show a $1^{\circ}$ running mean in longitude of the individual temperature fluctuations.

tion whatsoever. However, inspection of Fig. 2 suggests that the reason for this reduced performance could be because the surface winds in CS2 are significantly underestimated in the climate model compared to the mesoscale model, which would result in a significantly weaker parameterised response than in reality. (Poorer skill in the climate model representation of surface winds would be expected due to its poorly described resolved orography.) Finally, the comparison also shows, for all three case studies, that $\Delta T_{\text {CLIM }}$ completely fails to represent any temperature fluctuations, i.e. confirmation that the horizontal scale of the mountain waves are too small to be resolved by climate models, and hence their effects must be parameterised. Note that the climate model simulations of the three case studies were repeated at a higher N96 resolution $(192 \times 145$ grid points, or $1.875^{\circ} \times 1.25^{\circ}$ ), which also completely failed to resolve any temperature fluctuations over the AP (not shown).

Figure 6a and b compare $\Delta T_{\mathrm{MES}}$ and $\Delta T_{\mathrm{SSO}}$ for CS3 along a west-east cross section intersecting the AP at $70^{\circ} \mathrm{S}$, i.e. again selected to coincide with the location of its mountain wave event. Only results for CS3 are shown, as equivalent results for CS1 were largely similar. The predominant feature of the $\Delta T_{\mathrm{MES}}$ response is, as expected, a large-amplitude, vertically propagating mountain wave with phase lines tilting upstream with height, characterised by a horizontal wavelength of around $200 \mathrm{~km}$, a vertical wavelength of around $15 \mathrm{~km}$, and a amplitude of up to $15 \mathrm{~K}$ (in the lower stratosphere). Although the parameterisation scheme qualitatively captures the mesoscale model estimate of the temperature fluctuations in the lower stratosphere directly above the AP, it is clearly apparent that it (i) fails to capture the upstream tilt of the phase lines, i.e. its phase lines are horizontal and do not tilt with height, and (ii) significantly underestimates the amplitude of the temperature fluctuations. (Note that Fig. 6 also demonstrates that the approach used in Fig. 5 to assess the parameterised temperature fluctuations is a much more quantitative comparison than simply averaging over a long transect intersecting the AP, as the negative (cooling) and positive (warming) phases apparent in Fig. 6a would largely cancel each other out.)

The lack of phase tilt is due to the parameterised wave field being represented by a hydrostatic gravity wave launched from an isolated bell-shaped ridge for each grid box, which is then only propagated vertically through the column of air above. This simplification is also prohibitive in modelling the full downstream response. At climate model resolution the AP is multiple grid boxes wide as its resolved orography field is hugely smoothed/flattened (see Fig. 6) and is thus represented in the parameterisation as a series of very similar sub-grid ridges, while in the mesoscale model the AP is resolved as a dominant wide single ridge. Therefore the parameterisation produces a simplified broad response, which has smaller amplitude compared to the mesoscale model, across the AP, whereby any change in phase can only result from changes in $U$ and $N$ within each vertical column across the AP. Further comparison of the mesoscale model and climate model simulations in Figs. 7 and 8 shows, with the exception of the lower altitude parts of CS1 and CS3, that $U$ and $N$ simulated by the climate model lie within 

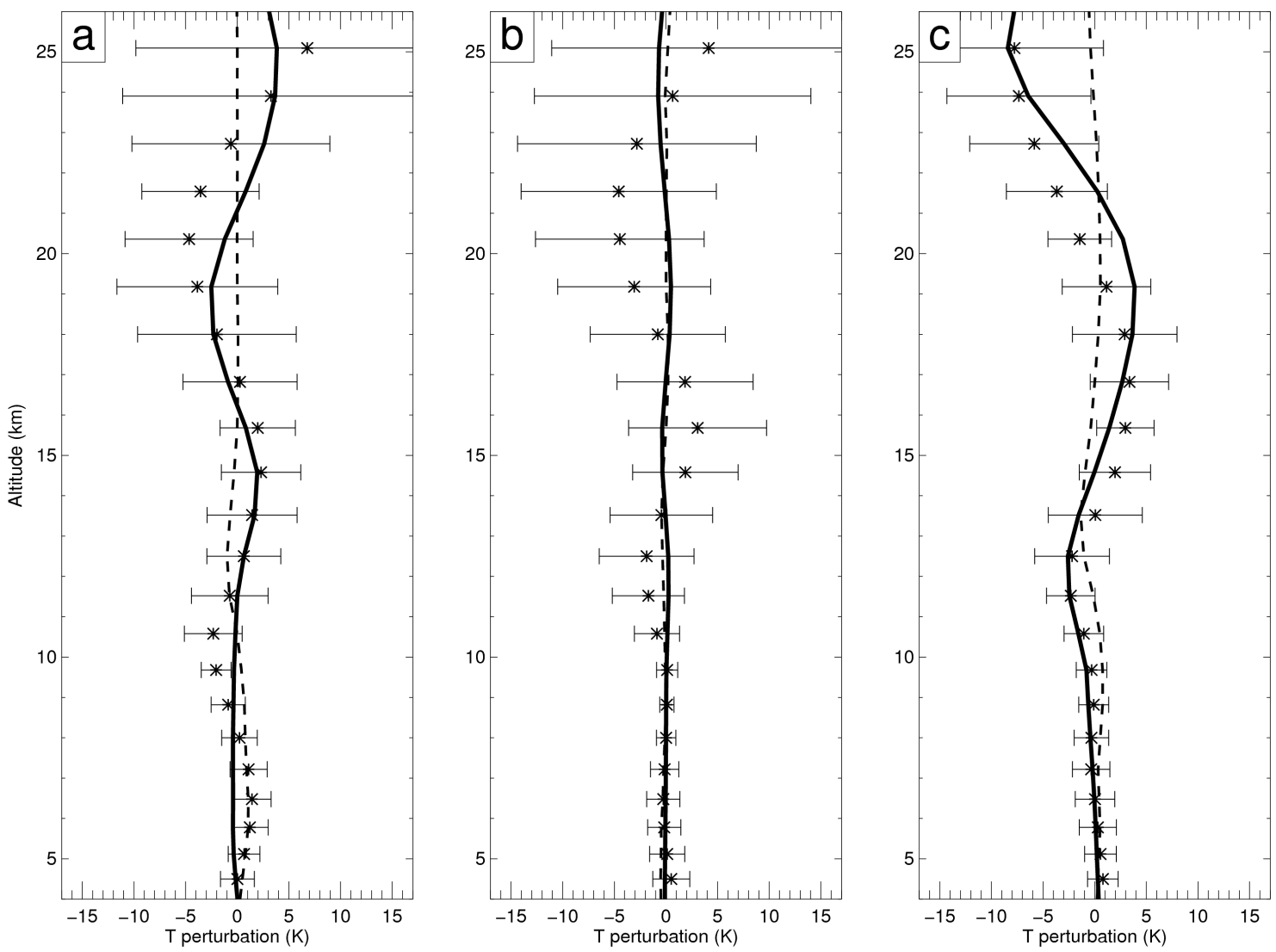

Figure 5. Vertical profile of temperature fluctuations (K) resolved by the climate model (dashed line), resolved by the mesoscale model (stars and horizontal bars), and parameterised by the mountain wave scheme $\Delta T_{\mathrm{SSO}}$ (solid line) at the time of the CS1 (a), CS2 (b), and CS3 (c) mountain wave events. See Table 1 for dates. The temperature fluctuations resolved by the climate model and parameterised by the scheme are for the grid boxes located at $\left(70^{\circ} \mathrm{S}, 63.75^{\circ} \mathrm{W}\right)$ for CS1, $\left(65.0^{\circ} \mathrm{S}, 60.0^{\circ} \mathrm{W}\right)$ for $\mathrm{CS} 2$, and $\left(70.0^{\circ} \mathrm{S}, 60^{\circ} \mathrm{W}\right)$ for $\mathrm{CS} 3$, i.e. selected to coincide with the location of their respective mountain wave events. These locations are displayed in Fig. 3 . The mesoscale model temperature fluctuations are the mean (stars) and spread ( \pm 2 standard deviations, horizontal bars) of all the mesoscale model points within the same climate model grid box.
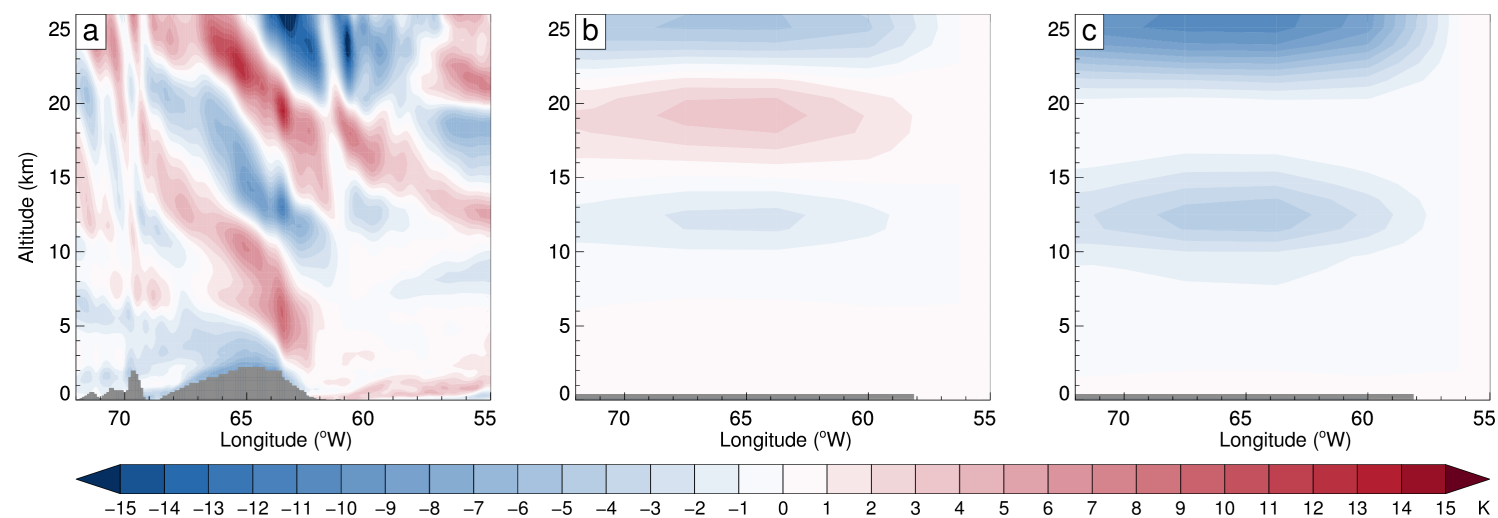

Figure 6. Vertical cross section intersecting the AP along a latitude band at $70^{\circ} \mathrm{S}$ of the temperature fluctuations (K) simulated by the mesoscale model (a) and parameterised by the mountain wave scheme (b) at the time of the CS3 mountain wave event. See Table 1 for dates. The grey shading indicates the height of the explicitly resolved orography. Also shown is the cooling phase of the parameterised temperature fluctuations $\Delta T_{\mathrm{SSO}}^{-}(\mathbf{c})$, i.e. the field which is actually coupled to the PSC scheme of the chemistry-climate model. 

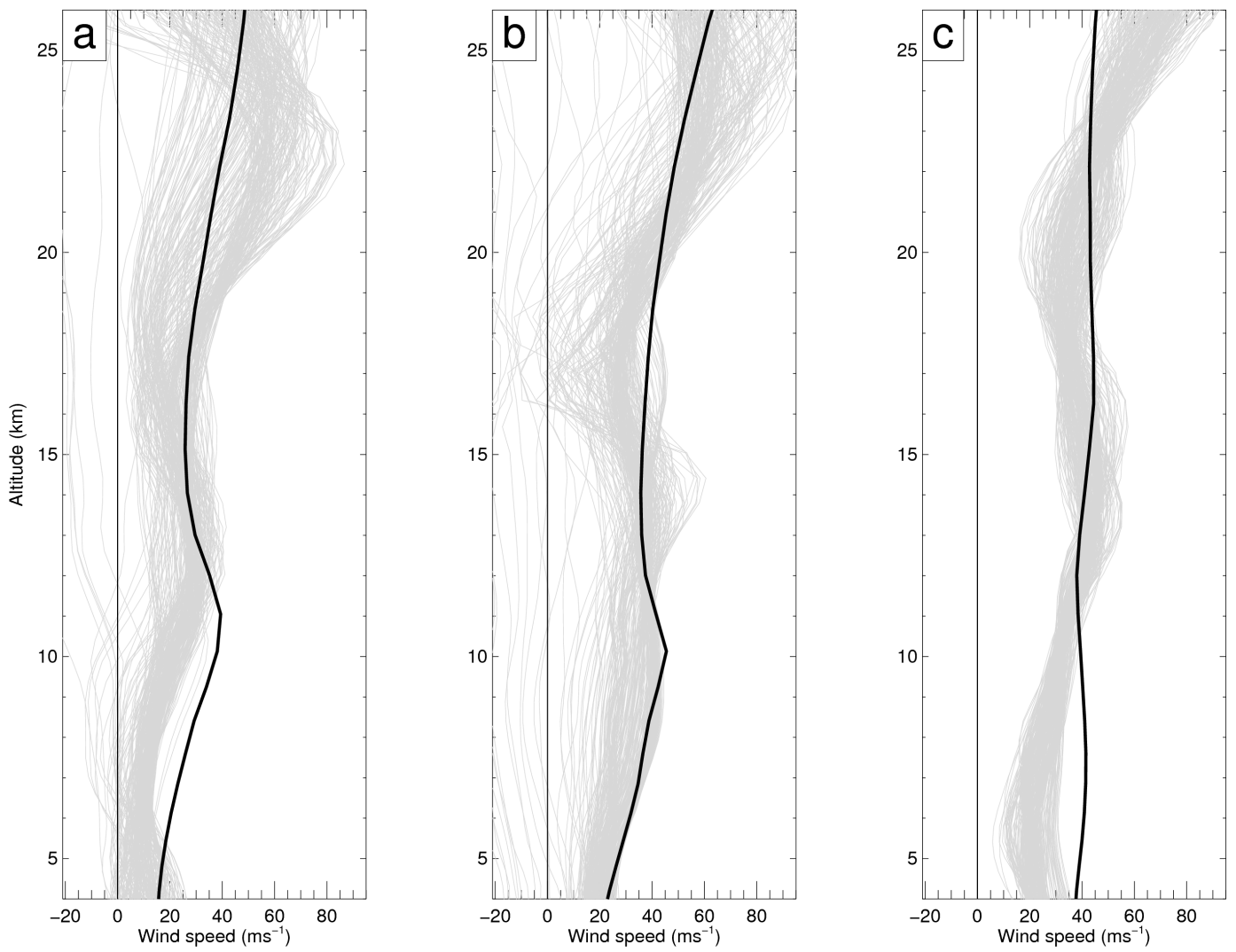

Figure 7. Vertical profile of the wind speed $U$ (resolved in the direction of the wave vector, which is taken to be the direction of the $850 \mathrm{hPa}$ wind vector) simulated by the climate model (black line) and the mesoscale model (grey lines) at the time of the CS1 (a), CS2 (b), and CS3 (c) mountain wave events. See Table 1 for dates. The climate model profile is for the same grid box used for Fig. 5. The mesoscale model profiles are for all the mesoscale model points within the same climate model grid box.

the spread of the mesoscale model responses, i.e. indicating that the large-scale atmospheric conditions responsible for the parameterised phase evolution are representative of the range of mesoscale model responses. Furthermore, given its broad-scale response, it cannot be expected that the parameterised temperature fluctuations match the amplitude of the fine-scale fluctuations simulated by the mesoscale model.

\section{Impact of the mountain wave parameterisation on PSC formation}

Having shown that the parameterised mountain-waveinduced temperature fluctuations are broadly consistent with the mesoscale model results, we can progress to assessing the impact of including the wave-induced cooling-phase $\Delta T_{\mathrm{SSO}}^{-}$ in the chemistry-climate model and coupling it to the PSC scheme, again concentrating on the AP. Figure 6c demonstrates the cooling-phase $\Delta T_{\mathrm{SSO}}^{-}$for CS3. It is apparent in this instance that it reaches values of around $-10 \mathrm{~K}$, which is significantly colder than the cold phases of the overall parameterised temperature fluctuations shown in Fig. 6b. In the first instance, we will examine the impact on the tem- peratures seen by the PSC scheme. Figure 9 shows for July at a height of $21 \mathrm{~km}$ the 30-year average difference in the frequency $f$ of the temperature falling below the 195 and $188 \mathrm{~K}$ thresholds for PSC formation of type Ia and II, respectively. The differences are between the frequency based on the explicitly resolved temperature $T_{\mathrm{CHEM}-\mathrm{CLIM}}$ plus $\Delta T_{\mathrm{SSO}}^{-}$ from the perturbation run, and the frequency based solely on the explicitly resolved temperature of the perturbation run, i.e. $f_{T_{\text {CHEM-CLIM }}+\Delta T_{\text {SSO }}^{-}}-f_{T_{\text {CHEN-CLIM }}}$. The differences in frequency are always positive, which is consistent with only mountain wave cooling being used. The results show that the impact of the mountain wave cooling over much of the $\mathrm{AP}$ is to increase the frequency that the $195 \mathrm{~K}$ threshold is exceeded, peaking over its northern tip with a frequency difference of 3 to 5 percentage points. By comparison, the impact on the $188 \mathrm{~K}$ temperature threshold is even more dramatic, resulting in differences which are both larger and extending much further south, peaking over Alexander Island to the south-west of the AP with a frequency difference of over 7 to 9 percentage points. The fact that the differences in $195 \mathrm{~K}$ threshold frequency are located predominately over the middle and northern sections of the AP is 

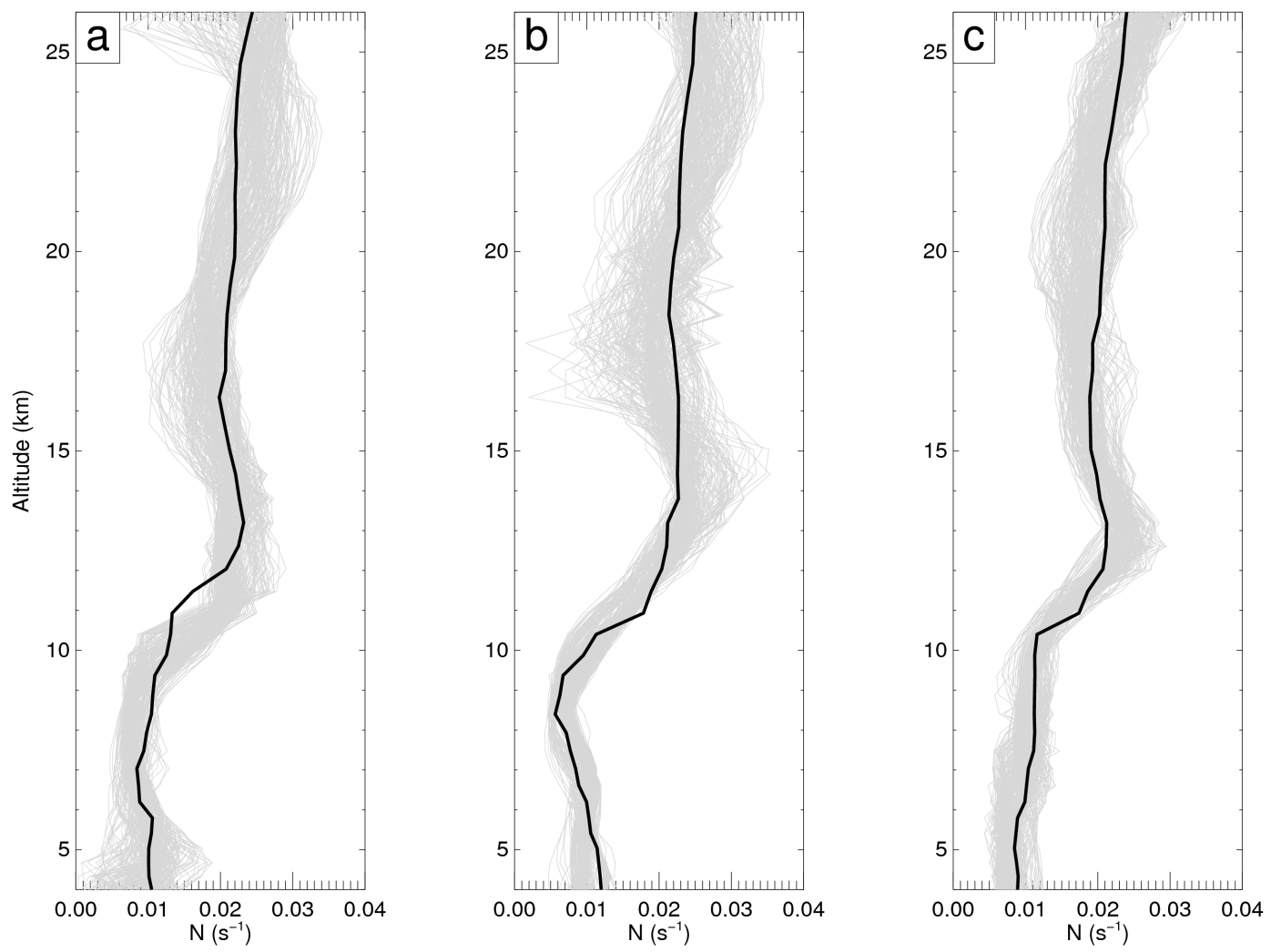

Figure 8. As Fig. 7, but for Brunt-Väisälä frequency $N\left(\mathrm{~s}^{-1}\right)$.

consistent with the climatological $195 \mathrm{~K}$ isotherm of the perturbation run being situated at approximately $-75^{\circ}$ latitude (not shown). Hence, any increase in the frequency of temperatures falling below $195 \mathrm{~K}$ as a result of the parameterisation can only occur northward of this, i.e. where the large-scale temperature is not already less than $195 \mathrm{~K}$. Similarly, the differences in $188 \mathrm{~K}$ threshold frequency which encompass the entire length of the AP are consistent with the model $188 \mathrm{~K}$ isotherm being situated southward of the $195 \mathrm{~K}$ isotherm (not shown). Figure 10 compares the 30-year temperature distribution based on $T_{\mathrm{CHEM}-\mathrm{CLIM}}+\Delta T_{\mathrm{SSO}}^{-}$of the perturbation run against that of $T_{\text {CHEM-CLIM }}$ for the perturbation run for the same N48 grid box used for CS1 in Figs. 5, 7, and 8, again for July and at $21 \mathrm{~km}$. As expected, inclusion of the parameterised mountain wave cooling shifts the temperature distribution to lower temperatures. In particular, it causes a longer left tail of the temperature distribution which extends down to $177 \mathrm{~K}$ (or $5 \mathrm{~K}$ colder than the temperature distribution based solely on $T_{\text {CHEM-CLIM }}$.

The effect of the parameterisation on PSCs is investigated by evaluating the 30-year average difference in PSC surface area density between the perturbation and control simulations (perturbation minus control). PSC surface area density controls the amount of reactive chlorine species produced, which cause ozone destruction. Figure 11 shows the difference in PSC surface area density at a height of $21 \mathrm{~km}$ for July. The perturbation run results in increases in surface area density for all PSCs (i.e. combined type I and II) of $6-10 \mu \mathrm{m}^{2} \mathrm{~cm}^{-3}$ over the AP and $>10 \mu \mathrm{m}^{2} \mathrm{~cm}^{-3}$ over the Bellingshausen Sea. Relative to the control run, these are equivalent to increases of more than $50 \%$ over the northern tip of the AP, and at least $30 \%$ over the Bellingshausen Sea. The Weddell Sea region shows a non-significant decrease in PSC surface area density. What is of note here is that PSC differences are occurring both upstream and downstream of the AP, i.e. removed from the actual region where the parameterisation acts directly. This is not unexpected. The chemistryclimate model is interactive: changing PSCs change chlorine activation, which impacts ozone loss. Changing ozone alters the heating rates that impact temperatures and circulation. What is diagnosed in Fig. 11 (and related figures) is the difference between two climate equilibrium states for identical boundary conditions (compare with, for example, Braesicke et al., 2013). Consequently, what is shown in the figures is locally strongly influenced by the additional parameterisation (adding localised cooling and thus producing more PSCs), but in regions away from the direct impact the response can be determined by feedback mechanisms. Figure 11 additionally separates these differences into their individual contributions from type I and type II PSCs. It is type I (type II) PSCs which are largely responsible for the overall PSC increase over the AP (Bellingshausen Sea). 


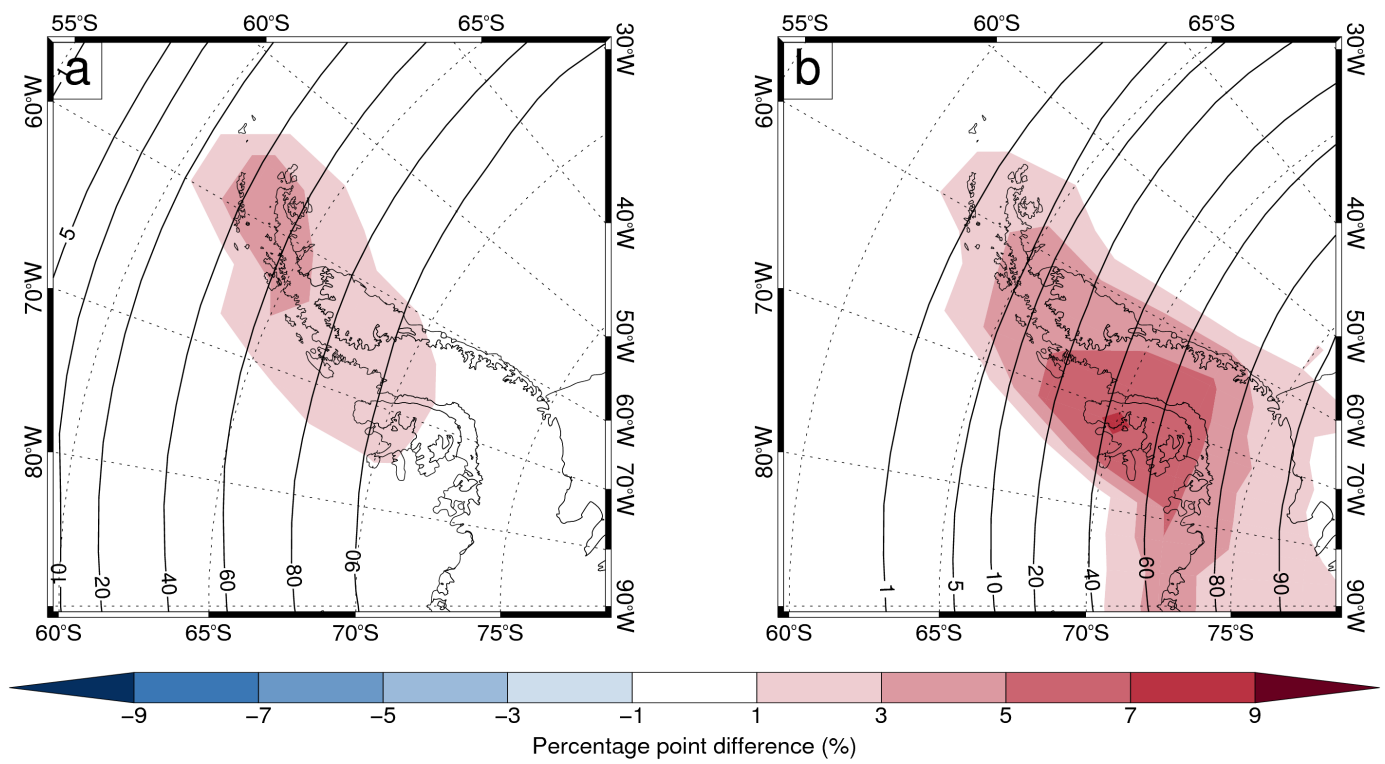

Figure 9. Impact of the mountain wave parameterisation during July at $21 \mathrm{~km}$ on the frequency $f$ the $195 \mathrm{~K}$ (a) and $188 \mathrm{~K}$ (b) temperature thresholds are exceeded over the AP in the perturbation run of the chemistry-climate model. Shown are the 30-year average percentage point differences between the frequency based on the explicitly resolved temperature $T_{\mathrm{CHEM}-\mathrm{CLIM}}$ plus the parameterised temperature

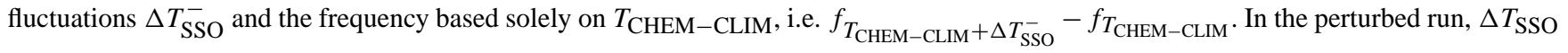
is represented by the cooling-phase $\Delta T_{\mathrm{SSO}}^{-}$only. The temperature thresholds of 195 and $188 \mathrm{~K}$ are assumed to be representative of the formation of type Ia and II PSCs, respectively. Both differences are computed from 6-hourly fields. The contours indicate the 30-year average frequency $f_{T_{\mathrm{CHEM}-\mathrm{CLIM}}}$. Also shown is the coastline of the AP.

\section{Summary and discussion}

Based on three case studies, this study demonstrated that (i) UM high-resolution $(4 \mathrm{~km})$ mesoscale model simulations are able to accurately simulate the large mountain-wave-induced temperature fluctuations in the lower stratosphere associated with strong westerly or north-westerly flow over the $\mathrm{AP}$, and that (ii) $\mathrm{UM}$ low-resolution $\left(2.5^{\circ} \times 3.75^{\circ}\right)$ climate model simulations are completely unable to resolve such temperature fluctuations. These fluctuations act as a significant source of localised PSC formation as they enable stratospheric temperatures which otherwise would remain above the temperature threshold for PSC formation to fall below it. With low resolution a model is unable to resolve such temperature fluctuations, and as a consequence it would underestimate mountain-wave-induced PSCs and the attendant PSCinduced ozone depletion.

To investigate the parameterisation of temperature fluctuations due to unresolved (sub-grid-scale) mountain waves, the parameterisation of Dean et al. (2007) was implemented in the UM climate model. It describes the vertical evolution of a linear hydrostatic wave forced by steady, stably stratified flow over a two-dimensional ridge. By determining the vertical evolution of the wave amplitude and the wave phase (alternative schemes such as Wells et al. (2011) solely compute the wave amplitude), the parameterisation is able to calculate the maximum downward and upward vertical displace- ment and subsequently the associated positive and negative temperature fluctuations. Its ability to represent the temperature fluctuations associated with the three case studies was assessed by comparison with the mesoscale model response. This demonstrated, for two out of the three case studies, that (i) the parameterised temperature fluctuations lie within the spread of the mesoscale model response, and (ii) the amplitude and phase of the parameterised temperature fluctuations are broadly in agreement with the mean mesoscale model response. In the remaining case study the parameterised response failed to capture any temperature fluctuations whatsoever, which we suggest is due to poor skill in capturing surface winds by the climate model. However, the comparison also showed that the parameterisation cannot represent the upstream tilt of the phase lines with height. This is due to it representing the AP by a series of independent sub-gridscale ridges which each launch a mountain wave vertically through the column of air above. Moreover, the parameterisation also does not represent trapped mountain lee waves, which can result in localised cooling (and the formation of PSCs) many hundreds of kilometres downstream (e.g. Dörnbrack et al., 1999). Notwithstanding these deficiencies, the current study illustrates that a more comprehensive treatment of sub-grid-scale mountain waves in a global climate model leads to realistic localised temperature change diagnostics.

Subsequently, we assessed and characterised the localised impact of the parameterised temperature fluctuations in a 


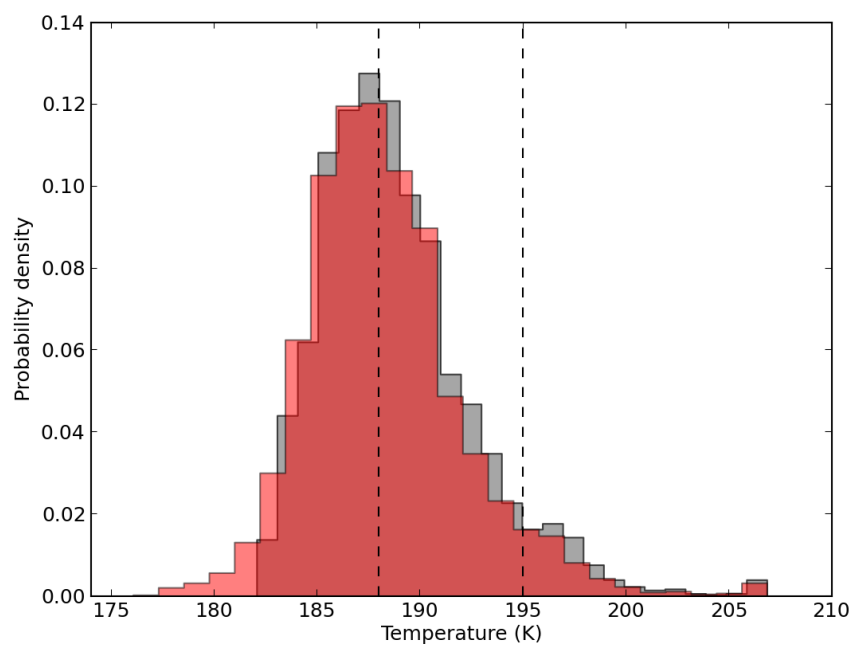

Figure 10. Impact of the mountain wave parameterisation during July at $21 \mathrm{~km}$ on the probability distributions of temperature over the AP in the perturbed run of the chemistry-climate model. Shown are the 30-year average temperature distributions based on the explicitly resolved temperature $T_{\mathrm{CHEM}-\mathrm{CLIM}}$ plus the parameterised temperature fluctuations $\Delta T_{\mathrm{SSO}}^{-}$(red colouring), and the frequency based solely on $T_{\text {CHEM-CLIM }}$ (grey colouring). Regions where the two distributions overlap are coloured a darker shade of red. Both temperature distributions are for the same N48 grid box used for CS1 in Figs. 5, 7, and 8 (i.e. $70^{\circ} \mathrm{S}, 63.75^{\circ} \mathrm{W}$ ). In the perturbed run, $\Delta T_{\mathrm{SSO}}$ is represented by the cooling-phase $\Delta T_{\mathrm{SSO}}^{-}$only. The temperature thresholds of 195 and $188 \mathrm{~K}$ are marked as dashed vertical lines and are assumed to be representative of the formation of type Ia and II PSCs, respectively. Both temperature distributions are computed from 6-hourly fields.

comprehensive chemistry-climate model. The formation of PSCs is dependent on the temperature being below a threshold value, and the argument that the warm phase is too short to lead to particle evaporation (Carslaw et al., 1999) means that the presence of PSCs is more strongly controlled by the cooling phase. It was found that adding the wave-induced cooling phase to the resolved temperature had a substantial impact on the frequency and magnitude of low temperatures which satisfy PSC thresholds, resulting in a regional $30-50 \%$ increase in PSC surface area density during July at a height of $21 \mathrm{~km}$ over the AP and the Bellingshausen Sea. It should be stressed that we were unable to compare these results with observations as (i) detailed measurements of Antarctic PSCs over a decadal timescale are not available at present (Austin et al., 2010) and (ii) global atmospheric reanalyses do not resolve small-scale temperature fluctuations.

Our decision to include only the cooling phase implies that this may lead to an overestimate of the impacts of the scheme, and that the diagnosed increase in PSC surface area density should perhaps be considered as an upper bound. Note that consideration of the (neglected) warm phase in the equilibrium PSC scheme would reduce the PSC surface area density change modelled towards the large-scale
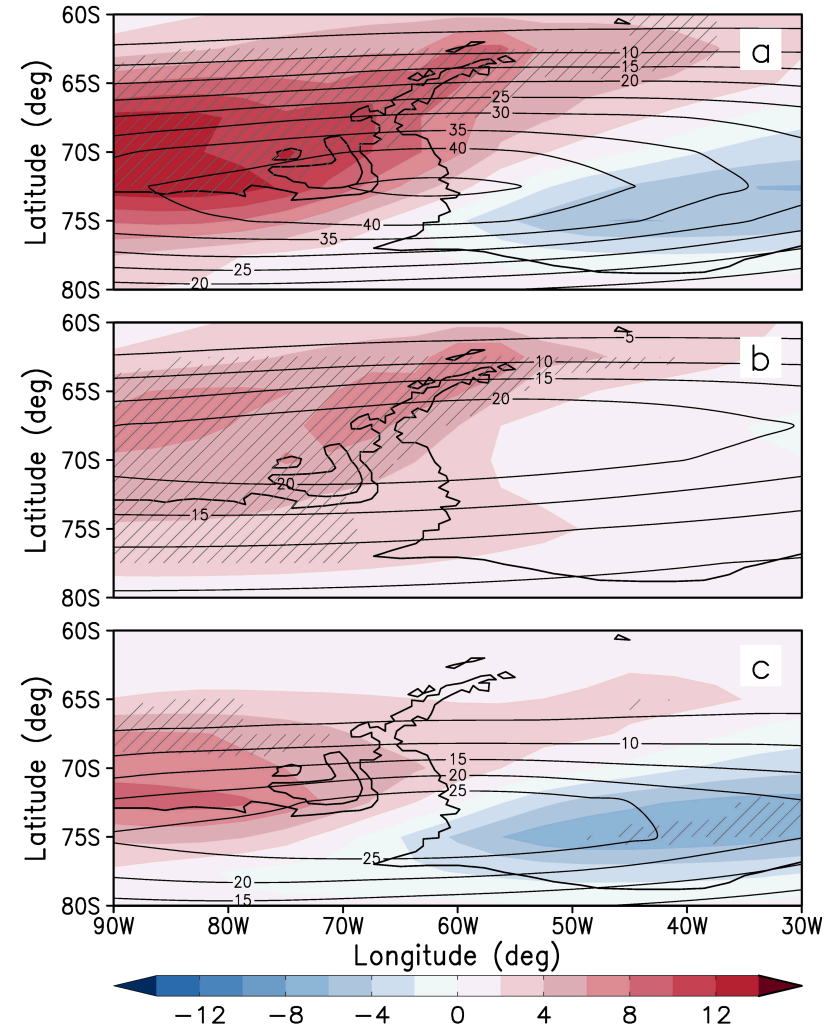

Figure 11. Impact of the mountain wave parameterisation during July at $21 \mathrm{~km}$ on PSC surface area density $\left(\mu \mathrm{m}^{2} \mathrm{~cm}^{-3}\right)$ over the AP in the chemistry-climate model. The shading indicates the 30 -year average difference in surface area density between the perturbation run and the control run (perturbation run minus the control run) for PSC types I and II (a), type I (b), and type II (c). The contours indicate the 30-year average PSC surface area density from the control run. Hatching denotes significance at the $95 \%$ confidence level using a two-tailed Student $t$ test. Also shown is the coastline of the AP.

solution obtained in the control integration. By contrast, in a microphysical scheme in which PSC particles are advected around, the particles could briefly exist in air which is above the threshold temperature during the wave-induced warming phase before temperature would fall once again to below the threshold, maintaining PSCs. We simulate this effect by using the cooling phase only. In future work we plan to insert the microphysical scheme DLAPSE (Denitrification by Lagrangian Particle Sedimentation) (Feng et al., 2011) into the UKCA module, and couple it to both the cooling and warming phases of the parameterised temperature fluctuations.

The simulation of PSC differences both upstream and downstream of the AP, and hence removed from the actual region where the parameterisation impacts temperatures directly, is suggestive of a new climate-equilibrium state being established in the model that allows non-local effects to occur. Investigation of this will be the subject of future study. Nevertheless, the parameterisation offers a method for im- 
proving lower stratospheric temperatures that more often satisfy conditions for PSC formation, the failure of which was suggested by Austin et al. (2010) to be one of the main reasons for the poor simulation of ozone depletion.

It is worth noting that other biases can affect the ability of chemistry-climate models to realistically simulate PSCs. For example, the failure of many models to represent the effects of non-orographic gravity wave drag can result in unrealistically cold temperatures in the Southern Hemisphere winter stratosphere (Orr et al., 2010), i.e. resulting in synoptic-scale temperatures which fall below the PSC temperature threshold when in reality they should be above it, which as a consequence cause the formation of too many PSCs and associated increased ozone losses (Austin and Butchard, 2003). Moreover, the equilibrium PSC scheme used by the UKCA module does not advect PSC particles (Feng et al., 2011). This means that the occurrence of circumpolar belts of PSCs which have been attributed to mountain-wave-induced PSCs over regions such as the AP would not be represented. However, DLAPSE uses a Lagrangian trajectory scheme and as such is able to transport PSC particles away from the region of formation (Feng et al., 2011). Further future work will also involve evaluating and improving the representation of PSC formation mechanisms in the chemistry-climate model via comparison with MIPAS (Michelson Interferometer for Passive Atmospheric Sounding) PSC observations (Spang et al., 2012), resulting in improved modelling and more reliable projections of both Antarctic ozone hole recovery and Arctic ozone.

Acknowledgements. The authors thank the two anonymous reviewers for their remarks which contributed to the improvement of the original manuscript. Thanks are also given to T. Phillips for providing much assistance in producing the figures, and to $\mathrm{S}$. Webster, T. Lachlan-Cope, C. Listowski, K. Carslaw, and G. Mann for useful discussions. This study is part of the British Antarctic Survey Polar Science for Planet Earth Programme. It was funded by the Natural Environment Research Council (grant no. NE/H022988/1). AIRS data are distributed by NASA Goddard Earth Science Data Information and Services Center. This work made use of the facilities HECToR, the UK's national high-performance-computing service, which is provided by UoE HPCx Ltd at the University of Edinburgh, Cray Inc and NAG Ltd, and funded by the Office of Science and Technology through EPSRC's High End Computing Programme.

Edited by: P. Jöckel

\section{References}

Alexander, J. M. and Barnet C. D.: Using satellite observations to constrain gravity wave parameterizations for global models, J. Atmos. Sci., 64, 1652-1665, doi:10.1175/JAS3897.1, 2007.

Alexander, J. M. and Teitelbaum, H.: Observation and analysis of a large amplitude mountain wave event over the Antarctic Peninsula, J. Geophys. Res., 112, D21103, doi:10.1029/2006JD008368, 2007.

Alexander, S. P., Klekociuk, A. R., Pitts, M. C., McDonald, A. J., and Arevalo-Torres, A.: The effect of orographic gravity waves on Antarctic polar stratospheric cloud occurrence and composition, J. Geophys. Res., 116, D06109, doi:10.1029/2010JD015184, 2011.

Alexander, S. P., Klekociuk, A. R., McDonald, A. J., and Pitts, M. C.: Quantifying the role of orographic gravity waves on polar stratospheric cloud occurrence in the Antarctic and the Arctic, J. Geophys. Res., 118, 11493-11507, doi:10.1002/2013JD020122, 2013.

Alfred, J., Fromm, M., Bevilacqua, R., Nedoluha, G., Strawa, A., Poole, L., and Wickert, J.: Observations and analysis of polar stratospheric clouds detected by POAM III and SAGE III during the SOLVE II/VINTERSOL campaign in the 2002/2003 Northern Hemisphere winter, Atmos. Chem. Phys., 7, 2151-2163, doi:10.5194/acp-7-2151-2007, 2007.

Aumann, H. H., Chahine, M. T., Gautier, C., Goldberg, M. D., Kalnay, E., McMillin, L. M., Revercomb, H., Rosenkranz, P. W., Smith, W. L., Staelin, D. H., Strow, L. L., and Susskind, J.: AIRS/AMSU/HSB on the Aqua mission: Design, science objective, data products, and processing systems, IEEE T. Geosci. Remote, 41, 253-264, doi:10.1109/TGRS.2002.808356, 2003.

Austin, J. and Butchart, N.: Coupled chemistry-climate model simulations for the period 1980 to 2020: Ozone depletion and the start of ozone recovery, Q. J. Roy. Meteor. Soc., 129, 3225-3249, doi:10.1256/qj.02.203, 2003.

Austin, J., Struthers, H., Scinocca, J., Plummer, D. A., Akiyoshi, H., Baumgaertner, A. J. G., Bekki, S., Bodeker, G. E., Braesicke, P., Brühl, C., Butchart, N., Chipperfield, M. P., Cugnet, D., Dameris, M., Dhomse, S., Frith, S., Garny, H., Gettelman, A., Hardiman, S. C., Jöckel, P., Kinnison, D., Kubin, A., Lamarque, J. F., Langematz, U., Mancini, E., Marchand, M., Michou, M., Morgenstern, O., Nakamura, T., Nielsen, J. E., Pitari, G., Pyle, J., Rozanov, E., Shepherd, T. G., Shibata, K., Smale, D., Teyssèdre, H., and Yamashita, Y.: Chemistry-climate model simulations of spring Antarctic ozone, J. Geophys. Res., 115, D00M11, doi:10.1029/2009JD013577, 2010.

Braesicke, P., Keeble, J., Yang, X., Stiller, G., Kellmann, S., Abraham, N. L., Archibald, A., Telford, P., and Pyle, J. A.: Circulation anomalies in the Southern Hemisphere and ozone changes, Atmos. Chem. Phys., 13, 10677-10688, doi:10.5194/acp-1310677-2013, 2013.

Campbell, J. R. and Sassen, K.: Polar stratospheric clouds at the South Pole from 5 years of continuous lidar data: Macrophysical, optical, and thermodynamic properties, J. Geophys. Res., 113, D20204, doi:10.1029/2007JD009680, 2008.

Cariolle, D., Muller, S., Cayla, F., and McCormick, M. P.: Mountain waves, polar stratospheric clouds, and ozone depletion over Antarctica, J. Geophys. Res., 94, 11233-11240, doi:10.1029/JD094iD09p11233, 1989.

Carslaw, K. S., Wirth, M., Tsias, A., Luo, B. P., Dörnbrack, A., Leutbecher, M., Volkert, H., Renger, W., Bacmeister, J. T., and Peter, T.: Particle microphysics and chemistry in remotely observed mountain polar stratospheric clouds, J. Geophys. Res., 103, 5785-5796, doi:10.1029/97JD03626, 1998a.

Carslaw, K. S., Wirth, M., Tsias, A., Luo, B. P., Dörnbrack, A., Leutbecher, M., Volkert, H., Renger, W., Bacmeister, J. T., 
Reimer, E., and Peter, Th.: Increased stratospheric ozone depletion due to mountain-induced atmospheric waves, Nature, 391, 675-678, 1998b.

Carslaw, K. S., Peter, T., Bacmeister, J. T., and Eckermann, S. D.: Widespread solid particle formation by mountain waves in the Arctic stratosphere, J. Geophys. Res., 104, 1827-1836, doi:10.1029/1998JD100033, 1999.

Dean, S. M., Flowerdew, J., Lawrence, B. N., and Eckermann, S. D.: Parameterisation of orographic cloud dynamics in a GCM, Clim. Dynam., 28, 581-597, doi:10.1007/s00382-006-0202-0, 2007.

Donlon, C. J., Martin, M., Stark, J. D., Roberts-Jones, J., Fiedler, E., and Wimmer, W.: The Operational Sea Surface Temperature and Sea Ice analysis (OSTIA), Remote Sens. Environ., 116, 140-158, doi:10.1016/j.rse.2010.10.017, 2011.

Dörnbrack, A., Leutbecher, M., Kivi, R., and Kyrö, E.: Mountainwave-induced record low stratospheric temperatures above northern Scandinavia, Tellus, 51A, 951-963, 1999.

Dörnbrack, A. and Leutbecher, M.: Relevance of mountain waves for the formation of polar stratospheric clouds over Scandinavia: A 20 year climatology, J. Geophys. Res., 106, 1583-1593, doi:10.1029/2000JD900250, 2001.

Dörnbrack, A., Birner, T., Fix, A., Flentje, H., Meister, A., Schmid, H., Browell, E. V., and Mahoney, M. J.: Evidence for inertia gravity waves forming in polar stratospheric clouds over Scandinavia, J. Geophys. Res., 107, 8287, doi:10.1029/2001JD000452, 2002.

Dörnbrack, A., Pitts, M. C., Poole, L. R., Orsolini, Y. J., Nishii, K., and Nakamura, H.: The 2009-2010 Arctic stratospheric winter general evolution, mountain waves and predictability of an operational weather forecast model, Atmos. Chem. Phys., 12, 36593675, doi:10.5194/acp-12-3659-2012, 2012.

Eckermann, S. D., Hoffmann, L., Höpfner, M., Wu, D. L., and Alexander, M. J.: Antarctic NAT PSC belt of June 2003: Observational validation of the mountain wave seeding hypothesis, Geophys. Res. Lett., 36, L02807, doi:10.1029/2008GL036629, 2009.

Eyring, V., Butchart, N., Waugh, D. W., Akiyoshi, H., Austin, J., Bekki, S., Bodeker, G. E., Boville, B. A., Brühl, C., Chipperfield, M. P., Cordero, E., Dameris, M., Deushi, M., Fioletov, V. E., Frith, S. M., Garcia, R. R., Gettelman, A., Giorgetta, M. A., Grewe, V., Jourdain, L., Kinnison, D. E., Mancini, E., Manzini, E., Marchand, M., Marsh, D. R., Nagashima, T., Newman, P. A., Nielsen, J. E., Pawson, S., Pitari, G., Plummer, D. A., Rozanov, E., Schraner, M., Shepherd, T. G., Shibata, K., Stolarski, R. S., Struthers, H., Tian, W., and Yoshiki, M.: Assessment of temperature, trace species and ozone in chemistry-climate model simulations of the recent past, J. Geophys. Res., 111, D22308, doi:10.1029/2006JD007327, 2006.

Eyring, V., Arblaster, J. M., Cionni, I., Sedláček, J., Perlwitz, J., Young, P. J., Bekki, S., Bergmann, D., Cameron-Smith, P., Collins, W. J., Faluvegi, G., Gottschaldt, K.-D., Horowitz, L. W., Kinnison, D. E., Lamarque, J.-F., Marsh, D. R., SaintMartin, D., Shindell, D. T., Sudo, K., Szopa, S., and Watanabe, S.: Long-term ozone changes and associated climate impacts in CMIP5 simulations, J. Geophys. Res., 118, 5029-5060, doi:10.1002/jgrd.50316, 2013.

Feng, W., Chipperfield, M. P., Davies, S., Mann, G. W., Carslaw, K. S., Dhomse, S., Harvey, L., Randall, C., and Santee, M. L.: Modelling the effect of denitrification on polar ozone depletion for
Arctic winter 2004/2005, Atmos. Chem. Phys., 11, 6559-6573, doi:10.5194/acp-11-6559-2011, 2011.

Grimsdell, A. W., Alexander, M. J., May, P. T., and Hoffmann, L.: Model study of waves generated by convection with direct validation via satellite, J. Atmos. Sci., 67, 1617-1631, doi:10.1175/2009JAS3197.1, 2010.

Hewitt, H. T., Copsey, D., Culverwell, I. D., Harris, C. M., Hill, R. S. R., Keen, A. B., McLaren, A. J., and Hunke, E. C.: Design and implementation of the infrastructure of HadGEM3: the nextgeneration Met Office climate modelling system, Geosci. Model Dev., 4, 223-253, doi:10.5194/gmd-4-223-2011, 2011.

Hoffmann, L. and Alexander, M. J.: Retrieval of stratospheric temperatures from Atmospheric Infrared Sounder radiance measurements for gravity wave studies, J. Geophys. Res., 114, D07105, doi:10.1029/2008JD011241, 2009.

Hoffmann, L. and Alexander, M. J.: Occurrence frequency of convective gravity waves during the North American thunderstorm season, J. Geophys. Res., 115, D20111, doi:10.1029/2010JD014401, 2010.

Hoffmann, L., Xue, X., and Alexander, M. J.: A global view of stratospheric gravity wave hotspots located with Atmospheric Infrared Sounder observations, J. Geophys. Res., 118, 416-434, doi:10.1029/2012JD018658, 2013.

Höpfner, M., Larsen, N., Spang, R., Luo, B. P., Ma, J., Svendsen, S. H., Eckermann, S. D., Knudsen, B., Massoli, P., Cairo, F., Stiller, G., v. Clarmann, T., and Fischer, H.: MIPAS detects Antarctic stratospheric belt of NAT PSCs caused by mountain waves, Atmos. Chem. Phys., 6, 1221-1230, doi:10.5194/acp-6-1221-2006, 2006.

Liu, H., Jezek, K., Li, B., Zhao, Z.: Radarsat Antarctic Mapping Project digital elevation model version 2, National Snow and Ice Data Center, Boulder, Colorado, available at: http://nsidc.org/ data/nsidc-0082.html (last access: January 2014), 2001.

Lott, F. and Miller, M.: A new subgrid scale orographic drag parameterization; its testing in the ECMWF model, Q. J. Roy. Meteor. Soc., 123, 101-127, doi:10.1002/qj.49712353704, 1997.

McDonald, A. J., George, S. E., and Woollands, R. M.: Can gravity waves significantly impact PSC occurrence in the Antarctic?, Atmos. Chem. Phys., 9, 8825-8840, doi:10.5194/acp-9-8825-2009, 2009.

McFarlane, N. A.: The effect of orographically excited gravity wave drag on the general circulation of the lower stratosphere and troposphere, J. Atmos. Sci., 44, 1775-1800, doi:10.1175/15200469(1987)044<1775:TEOOEG> 2.0.CO;2, 1987.

Morgenstern, O., Braesicke, P., O'Connor, F. M., Bushell, A. C., Johnson, C. E., Osprey, S. M., and Pyle, J. A.: Evaluation of the new UKCA climate-composition model - Part 1: The stratosphere, Geosci. Model Dev., 2, 43-57, doi:10.5194/gmd-2-432009, 2009.

Morgenstern, O., Giorgetta, M. K.., Shibata, K., Eyring, V., Waugh, D. W., Shepherd, T. G., Akiyoshi, H., Austin, J., Baumgaertner, A. J. G., Bekki, S., Braesicke, P., Brühl, C., Chipperfield, M. P., Cugnet, D., Dameris, M., Dhomse, S., Frith, S. M., Garny, H., Gettelman, S., Hardiman, S. C., Hegglin, M. I., Jöckel, P., Kinnison, D. E., Lamarque, J.-F., Mancini, E., Manzini, E., Marchand, M., Michou, M., Nakamura, T., Nielsen, J. E., Olivié, D., Pitari, G., Plummer, D. A., Rozanov, E., Scinocca, J. F., Smale, D., Teyssèdre, H., Toohey, M., Tian W., and Yamashita, Y.:Review of the formulation of present-generation stratospheric chemistry- 
climate models and associated external forcings, J. Geophys. Res., 115, D00M02, doi:10.1029/2009JD013728, 2010.

Noel, V. and Pitts, M.: Gravity wave events from mesoscale simulations, compared to polar stratospheric clouds observed from spaceborne lidar over the Antarctic Peninsula, J. Geophys. Res., 117, D11207, doi:10.1029/2011JD017318, 2012.

Noel, V., Hertzog, A., and Chepfer, H.: CALIPSO observations of wave-induced PSCs with near-unity optical depth over Antarctica in 2006-2007, J. Geophys. Res., 114, D05202, doi:10.1029/2008JD010604, 2009.

Orr, A., Marshall, G., Hunt, J. C. R., Sommeria, J., Wang, C., van Lipzig, N., Cresswell, D., and King, J. C.: Characteristics of airflow over the Antarctic Peninsula and its response to recent strengthening of westerly circumpolar winds, J. Atmos. Sci., 65, 1396-1413, doi:10.1175/2007JAS2498.1, 2008.

Orr, A., Bechtold, P., Scinocca, J., Ern, M., and Janiskova, M.: Improved middle atmosphere climate and forecasts in the ECMWF model through a nonorographic gravity wave drag parameterization, J. Climate, 23, 5905-5926, doi:10.1175/2010JCLI3490.1, 2010.

Orr, A., Bracegirdle T. J., Hoskings, J. S., Jung, T., Haigh, J. D., Phillips, T., and Feng, W.: Possible dynamical mechanisms for Southern Hemisphere climate change due to the ozone hole, J. Atmos. Sci., 69, 2917-2932, doi:10.1175/JAS-D-11-0210.1, 2012.

Orr, A., Phillips, T., Webster, S., Elvidge, A., Weeks, M., Hosking, J. S., and Turner, J.: Met Office Unified Model high resolution simulations of a strong wind event in Antarctica, Q. J. Roy. Meteor. Soc., 140, 2287-2297, doi:10.1002/qj.2296, 2014.

Pawson, S., Naujokat, B., and Labitzke, K.: On the polar stratospheric cloud formation potential of the northern stratosphere, J. Geophys. Res., 100, 23215-23225, doi:10.1029/95JD01918, 1995.

Plougonven, R., Hertzog, A., and Teitelbaum, H.: Observations and simulations of large-amplitude mountain wave breaking over the Antarctic Peninsula, J. Geophys. Res., 113, D16113, doi:10.1029/2007JD009739, 2008.

Plougonven, R., Arsac, A., Hertzong, A., Guez, L., and Vial, F.: Sensitivity study for mesoscale simulations of gravity waves above Antarctica during Vorcore, Q. J. Roy. Meteor. Soc., 136, 1371-1377, doi:10.1002/qj.639, 2010.

Polvani, L. M., Previdi, M., and Deser, C.: Large cancellation, due to ozone recovery, of future Southern Hemisphere atmospheric circulation trends, Geophys. Res. Lett., 38, L04707, doi:10.1029/2011GL046712, 2011.
Reinecke, P. and Durran, D. R.: The over-amplification of gravity waves in numerical solutions to flow over topography, Mon. Weather Rev., 137, 1533-1549, doi:10.1175/2008MWR2630.1, 2009.

Roscoe, H. K., Jones, A. E., and Lee, A. M.: Midwinter start to Antarctic ozone depletion: Evidence from observations and models, Science, 278, 93-96, doi:10.1126/science.278.5335.93, 1997.

Solomon, S.: Stratospheric ozone depletion: A review of concepts and history, Rev. Geophys., 37, 275-316, doi:10.1029/1999RG900008, 1999.

Spang, R., Arndt, K., Dudhia, A., Höpfner, M., Hoffmann, L., Hurley, J., Grainger, R. G., Griessbach, S., Poulsen, C., Remedios, J. J., Riese, M., Sembhi, H., Siddans, R., Waterfall, A., and Zehner, C.: Fast cloud parameter retrievals of MIPAS/Envisat, Atmos. Chem. Phys., 12, 7135-7164, doi:10.5194/acp-12-71352012, 2012.

SPARC: SPARC Report on the Lifetimes of Stratospheric OzoneDepleting Substances, Their Replacements, and Related Species, edited by: Ko, M., Newman, P., Reimann, S., and Strahan S., SPARC Report No. 6, WCRP-15/2013, Zurich, Switzerland, 255 pp., 2013.

Thompson, D. W. J., Solomon, S., Kushner, P. J., England, M. H., Grise, K. M., and Karoly, D. J.: Signatures of the Antarctic ozone hole in Southern Hemisphere surface climate change, Nat. Geosci., 4, 741-749, 2011.

Webster, S., Brown, A. N., Cameron, D. R., and Jones, C. P.: Improvements to the representation of orography in the Met Office Unified Model, Q. J. Roy. Meteor. Soc., 129, 1989-2010, doi:10.1256/qj.02.133, 2003.

Webster, S., Uddstrom, M., Oliver, H., and Vosper, S.: A high-resolution modelling case study of a severe weather event over New Zealand, Atmos. Sci. Lett., 9, 119-128, doi:10.1002/asl.172, 2008

Wells, H., Vosper, S. B., and Yan, X.: An assessment of a mountainwave parametrization scheme using satellite observations of stratospheric gravity waves, Q. J. Roy. Meteor. Soc., 137, 819828, doi:10.1002/qj.790, 2011.

$\mathrm{Wu}$, D. L.: Mesoscale gravity wave variances from AMSU-A radiances, Geophys. Res. Lett., 31, L12114, doi:10.1029/2004GL019562, 2004.

Wu, D. L. and Eckermann, S. D.: Global gravity wave variances from Aura MLS: Characteristics and interpretation, J. Atmos. Sci., 65, 3695-3718, doi:10.1175/2008JAS2489.1, 2008. 